Supporting Information for

\title{
Molecular Imaging of Peroxynitrite with HKGreen-4 in Live Cells and Tissues
}

Tao Peng, ${ }^{\dagger, \downarrow}$ Nai-Kei Wong, ${ }^{\dagger, \downarrow}$ Xingmiao Chen, ${ }^{\zeta}$ Yee-Kwan Chan, ${ }^{\S}$ Zhenning Sun, ${ }^{\dagger}$ Jun Jacob $\mathrm{Hu},{ }^{\dagger}$ Jiangang Shen, ${ }^{\zeta}$ Hani El-Nezami, ${ }^{\S}$ and Dan Yang ${ }^{* \dagger}$

†Morningside Laboratory for Chemical Biology and Department of Chemistry, ¿School of Chinese Medicine, and sSchool of Biological Sciences, The University of Hong Kong, Pokfulam Road, Hong Kong, P. R. China

\section{Contents}

1. General Methods 2

2. Syntheses of Probes 2

3. General Protocols for Photophysical Characterization of Probes 13

$\begin{array}{ll}\text { 4. Probe Screening } & 14\end{array}$

5. Photophysical Characterization of HKGreen-4 for Peroxynitrite Detection 17

6. Reaction of HKGreen-4 with Peroxynitrite 20

7. Biological Assays of HKGreen-4 22

8. NMR spectra 34

9. Reference 41 


\section{General Methods}

All chemicals were purchased from Aldrich or Fluka, and used as received without further purification. All reactions were performed in oven-dried apparatus under an inert atmosphere (e.g, Ar or $\mathrm{N}_{2}$ ) when necessary. All reagents and solvents for reactions were used as received from commercial sources unless otherwise stated. Dichloromethane, toluene, DMF, and pyridine were distilled from calcium hydride. THF and dioxane were distilled from sodium/benzophenone.

Air and moisture-sensitive compounds were introduced via syringes through rubber septa. Reactions were monitored by thin layer chromatography (TLC) using E. Merck silica gel 60 precoated glass plates with $0.25 \mathrm{~mm}$ thickness. Components were visualized by illumination with a shortwavelength ultra-violet light and/or staining in phosphomolybdic acid (PMA) or $\mathrm{KMnO}_{4}$ solution followed by heating. Flash column chromatography was performed using the indicated solvents on E. Merck silica gel 60 (230-400 mesh ASTM).

Unless otherwise stated, NMR spectra were recorded in $\mathrm{CDCl}_{3}$ or $\mathrm{CD}_{3} \mathrm{OD}$ at ambient temperature on a Bruker Avance DPX 300 Fourier Transform Spectrometer operating at $300 \mathrm{MHz}$ for ${ }^{1} \mathrm{H}$ and at $75.47 \mathrm{MHz}$ for ${ }^{13} \mathrm{C}$ or Bruker Avance DPX 400 Fourier Transform Spectrometer operating at $400 \mathrm{MHz}$ for ${ }^{1} \mathrm{H}$ and at $100.6 \mathrm{MHz}$ for ${ }^{13} \mathrm{C}$. ${ }^{1} \mathrm{H}$ NMR chemical shifts were reported using tetramethylsilane (TMS, $\delta 0.00 \mathrm{ppm})$ or $\mathrm{CD}_{3} \mathrm{OD}\left(\mathrm{CD}_{3}, \delta 3.31 \mathrm{ppm}\right)$ as internal standard. ${ }^{13} \mathrm{C}$ NMR chemical shifts were reported using the central line of $\mathrm{CDCl}_{3}(\delta 77.00 \mathrm{ppm})$ or $\mathrm{CD}_{3} \mathrm{OD}(\delta 49.00 \mathrm{ppm})$ as internal standard.

Mass spectra were recorded with a Finnigan MAT 95 mass spectrometer for both low resolution and high resolution analysis. HPLC analysis was performed with an Agilent 1100 HPLC system.

\section{Syntheses of Probes}

Scheme S1. Structures of the new series of rhodol-based fluorescent probes for detecting peroxynitrite<smiles>[R]c1ccc(N(C)c2ccc3c(-c4ccccc4C(=O)O)c4ccc(=O)cc-4oc3c2)cc1</smiles> 
Scheme S2. Synthetic scheme for compounds 1 and 2
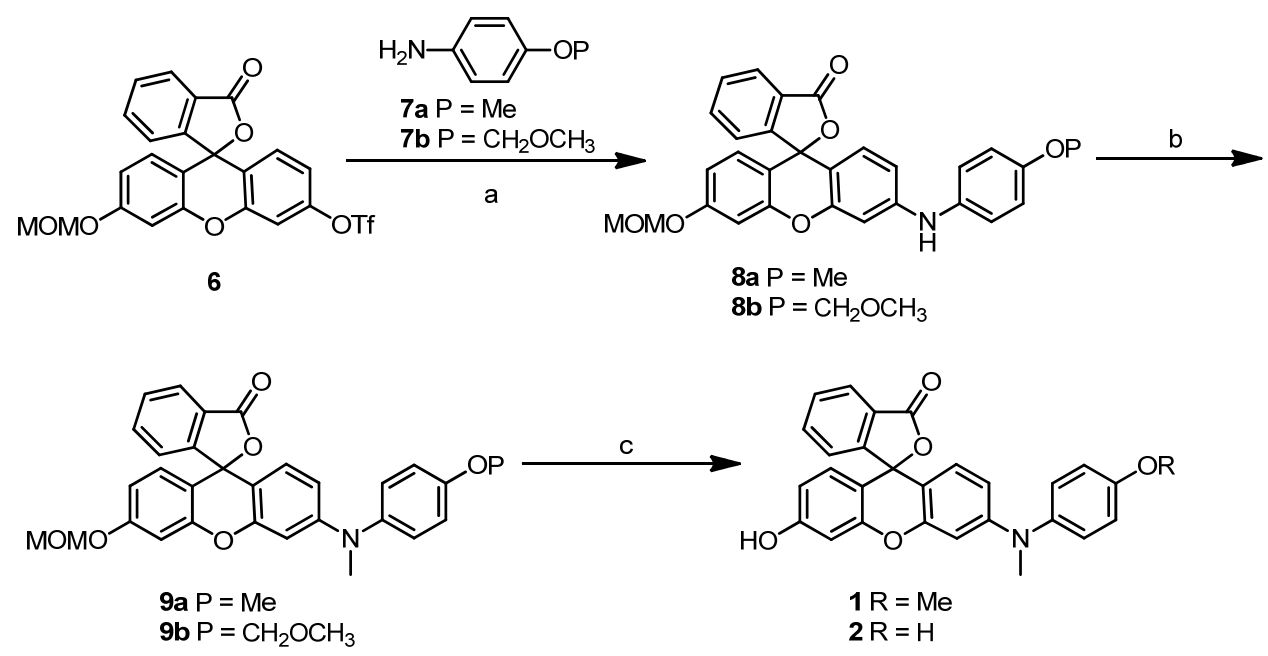

Reagents and Conditions: (a) $\mathrm{Pd}(\mathrm{OAc})_{2}$, BINAP, $\mathrm{Cs}_{2} \mathrm{CO}_{3}$, toluene, $100{ }^{\circ} \mathrm{C}, 20 \mathrm{~h}, 85 \%$ yield for 8a, and $82 \%$ yield for $\mathbf{8 b}$; (b) $\mathrm{NaH}$, THF, MeI, $12 \mathrm{~h}, 83 \%$ yield for $\mathbf{9 a}$, and $76 \%$ yield for $\mathbf{9 b}$; (c) $\mathrm{TFA}, \mathrm{CH}_{2} \mathrm{Cl}_{2}$, $0{ }^{\circ} \mathrm{C}$ to rt, $2 \mathrm{~h}, 92 \%$ yield for 1 , and $90 \%$ yield for 2 .

\section{Synthesis of compound $\mathbf{7 b}$}

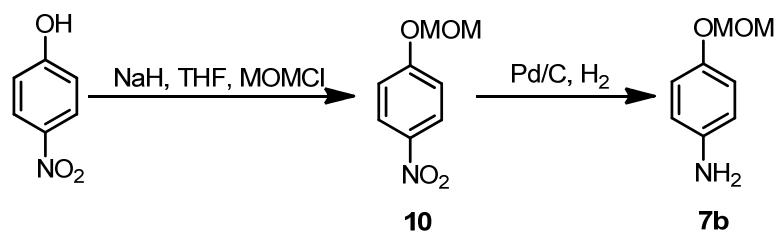

To a solution of $p$-nitrophenol $(1.39 \mathrm{~g}, 10 \mathrm{mmol})$ in THF $(40 \mathrm{~mL})$ was added NaH $(0.6 \mathrm{~g}, 15$ $\mathrm{mmol}, 60 \%$ in mineral oil) in small portions at $0{ }^{\circ} \mathrm{C}$ with vigorously stirring. After half an hour, $\mathrm{MOMCl}$ $(1.2 \mathrm{~mL}, 15 \mathrm{mmol})$ was then introduced into the above suspension. The mixture was stirred at room temperature for $3 \mathrm{~h}$ and quenched with water. The resulting mixture was extracted with diethyl ether. The organic solution was then dried over anhydrous sodium sulfate and concentrated to provide the crude product 10 (1.80 g, 98\% yield), which was directly used for the next step without further purification. Characterization data of 10: ${ }^{1} \mathrm{H}$ NMR $\left(300 \mathrm{MHz}, \mathrm{CDCl}_{3}\right) \delta 8.18(\mathrm{~d}, J=12.6 \mathrm{~Hz}, 2 \mathrm{H}), 7.11$ $(\mathrm{d}, J=12.6 \mathrm{~Hz}, 2 \mathrm{H}), 5.27$ (s, 2H), 3.50 (s, 3H); ${ }^{13} \mathrm{C} \mathrm{NMR}\left(75.5 \mathrm{MHz}, \mathrm{CDCl}_{3}\right) \delta$ 162.2, 125.7, 116.0, 103.3, 94.3, 56.4; LRMS (EI) m/z (\%) $183\left(\mathrm{M}^{+}\right.$; 49), 137 (100); HRMS (EI) for $\mathrm{C}_{8} \mathrm{H}_{9} \mathrm{NO}_{4}\left(\mathrm{M}^{+}\right)$: calcd 183.0532, Found: 183.0529. 
To a solution of 10 (1.80 g, $10 \mathrm{mmol}$ ) in $\mathrm{MeOH}$ was slowly added palladium (180 mg, 10\% on activated carbon powder, $10 \%$ on the weight of 10 ). The mixture was hydrogenated for $4 \mathrm{~h}$ at room temperature. The mixture was then filtered through a pad of Celite, and the filtrate was concentrated in vacuo to quantitatively give the product $7 \mathbf{b}$ ( $1.50 \mathrm{~g}, 98 \%$ yield), which was directly used for the next step without further purification. Characterization data of $7 \mathbf{b}:{ }^{1} \mathrm{H}$ NMR $\left(400 \mathrm{MHz}, \mathrm{CDCl}_{3}\right) \delta 6.87(\mathrm{~d}$, $J=8.8 \mathrm{~Hz}, 2 \mathrm{H}), 6.63(\mathrm{~d}, J=8.8 \mathrm{~Hz}, 2 \mathrm{H}), 5.07(\mathrm{~s}, 2 \mathrm{H}), 3.47(\mathrm{~s}, 3 \mathrm{H}) ;{ }^{13} \mathrm{C} \mathrm{NMR}\left(100 \mathrm{MHz}, \mathrm{CDCl}_{3}\right) \delta$ $150.2,141.0,117.8,116.2,95.5,55.8$.

\section{Synthesis of compound $8 \boldsymbol{a}$}

Compound 8a was synthesized from the coupling reaction between $\mathbf{6}$ and $p$-anisidine $7 \mathbf{a}$, 1.2 equiv) in $85 \%$ yield according to a procedure reported previously. ${ }^{1}$ Characterization data of $8 \mathrm{a}:{ }^{1} \mathrm{H}$ $\operatorname{NMR}\left(400 \mathrm{MHz}, \mathrm{CDCl}_{3}\right) \delta 8.03(\mathrm{~d}, J=7.4 \mathrm{~Hz}, 1 \mathrm{H}), 7.70-7.60(\mathrm{~m}, 2 \mathrm{H}), 7.21(\mathrm{~d}, J=7.4 \mathrm{~Hz}, 1 \mathrm{H}), 7.14$ $(\mathrm{d}, J=8.9 \mathrm{~Hz}, 2 \mathrm{H}), 6.94-6.93(\mathrm{~m}, 1 \mathrm{H}), 6.91(\mathrm{~d}, J=8.9 \mathrm{~Hz}, 2 \mathrm{H}), 6.73-6.71(\mathrm{~m}, 3 \mathrm{H}), 6.60(\mathrm{~d}, J=8.6$ $\mathrm{Hz}, 1 \mathrm{H}), 6.52(\mathrm{dd}, J=8.6,2.3 \mathrm{~Hz}, 1 \mathrm{H}), 5.79(\mathrm{br}, 1 \mathrm{H}), 5.20(\mathrm{~s}, 2 \mathrm{H}), 3.84(\mathrm{~s}, 3 \mathrm{H}), 3.49$ (s, 3H); ${ }^{13} \mathrm{C} \mathrm{NMR}$ $\left(100 \mathrm{MHz}, \mathrm{CDCl}_{3}\right) \delta 169.4,158.6,156.1,153.0,152.5,152.3,147.8,134.7(\mathrm{CH}), 133.7,129.4(\mathrm{CH})$, $128.9(\mathrm{CH}), 128.8(\mathrm{CH}), 126.8,124.7(\mathrm{CH}), 123.9(\mathrm{CH}), 123.8(\mathrm{CH}), 116.0,114.6(\mathrm{CH}), 112.5(\mathrm{CH})$, $111.4(\mathrm{CH}), 108.7,103.4(\mathrm{CH}), 100.4(\mathrm{CH}), 94.2\left(\mathrm{CH}_{2}\right), 83.8,56.0\left(\mathrm{CH}_{3}\right), 55.4\left(\mathrm{CH}_{3}\right)$; LRMS (EI) m/z. (\%) 481 (M+; 48), 437 (100); HRMS (EI) for $\mathrm{C}_{29} \mathrm{H}_{23} \mathrm{NO}_{6}\left(\mathrm{M}^{+}\right)$: calcd 481.1525, Found: 481.1520.

\section{Synthesis of compound 9 a}

To a solution of $\mathbf{8 a}(120 \mathrm{mg}, 0.25 \mathrm{mmol})$ in THF $(5 \mathrm{~mL})$ at $0{ }^{\circ} \mathrm{C}$ was added $\mathrm{NaH}(60 \%$ in mineral oil, $12 \mathrm{mg}, 0.3 \mathrm{mmol})$. The suspension was stirred for half an hour and then MeI (30 $\mu \mathrm{L}, 0.50$ mmol) was introduced. The mixture was stirred at room temperature overnight and then quenched with water. The mixture was diluted with ethyl acetate $(20 \mathrm{~mL})$, washed with $1 \mathrm{~N}$ hydrochloric acid and brine. After dried over anhydrous sodium sulfate the organic solution was concentrated in vacuo and the residue was purified by silica gel column chromatography to give compound $\mathbf{9 a}$ (103 $\mathrm{mg}, 83 \%$ yield). ${ }^{1} \mathrm{H}$ NMR $\left(400 \mathrm{MHz}, \mathrm{CDCl}_{3}\right) \delta 7.99(\mathrm{~d}, J=7.4 \mathrm{~Hz}, 1 \mathrm{H}), 7.66-7.56(\mathrm{~m}, 2 \mathrm{H}), 7.17(\mathrm{~d}, J=7.4 \mathrm{~Hz}$, 1H), $7.12(\mathrm{~d}, J=8.9 \mathrm{~Hz}, 2 \mathrm{H}), 6.92-6.90(\mathrm{~m}, 3 \mathrm{H}), 6.68-6.67(\mathrm{~m}, 2 \mathrm{H}), 6.53-6.50(\mathrm{~m}, 2 \mathrm{H}), 6.36(\mathrm{dd}$, $J=8.6,2.3 \mathrm{~Hz}, 1 \mathrm{H}), 5.18(\mathrm{~s}, 2 \mathrm{H}), 3.82(\mathrm{~s}, 3 \mathrm{H}), 3.46(\mathrm{~s}, 3 \mathrm{H}), 3.27$ (s, 3H); ${ }^{13} \mathrm{C} \mathrm{NMR}\left(100 \mathrm{MHz}, \mathrm{CDCl}_{3}\right)$ $\delta$ 169.4, 158.5, 157.3, 153.0, 152.5, 152.2, 151.4, 140.4, $134.6(\mathrm{CH}), 129.3(\mathrm{CH}), 128.9(\mathrm{CH}), 128.2(\mathrm{CH})$, $127.8(\mathrm{CH}), 126.9,124.7(\mathrm{CH}), 123.8(\mathrm{CH}), 116.3,114.9(\mathrm{CH}), 114.6,112.6,112.4(\mathrm{CH}), 110.5(\mathrm{CH})$, 107.1, $103.4(\mathrm{CH}), 100.0(\mathrm{CH}), 94.2\left(\mathrm{CH}_{2}\right), 83.7,56.0\left(\mathrm{CH}_{3}\right), 55.3\left(\mathrm{CH}_{3}\right), 40.2\left(\mathrm{CH}_{3}\right) ; \mathrm{LRMS}(\mathrm{EI}) \mathrm{m} / \mathrm{z}$ (\%) 495 ( $\mathrm{M}^{+}$; 35), 452 (100); HRMS (EI) for $\mathrm{C}_{30} \mathrm{H}_{25} \mathrm{NO}_{6}\left(\mathrm{M}^{+}\right)$: calcd 495.1682, Found: 495.1685. 
Synthesis of compound 1

To a solution of $\mathbf{9 a}(103 \mathrm{mg}, 0.21 \mathrm{mmol})$ in dry $\mathrm{CH}_{2} \mathrm{Cl}_{2}(3 \mathrm{~mL})$ was added trifluoroacetic acid $(3 \mathrm{~mL})$ dropwise at $0{ }^{\circ} \mathrm{C}$. The resulting solution was stirred at room temperature until TLC indicated all starting materials were consumed. The mixture was then concentrated in vacuo and azeotroped with toluene three times. The residue was dissolved in ethyl acetate and washed with saturated $\mathrm{NaHCO}_{3}$, followed by water and brine. The organic solution was concentrated and the resulting residue was purified by silica gel column chromatography to give compound $\mathbf{1}$ (87 $\mathrm{mg}, 92 \%$ yield). ${ }^{1} \mathrm{H}$ NMR (400 $\left.\mathrm{MHz}, \mathrm{CD}_{3} \mathrm{OD}\right) \delta 8.33(\mathrm{~d}, J=7.5 \mathrm{~Hz}, 1 \mathrm{H}), 7.86-7.80(\mathrm{~m}, 2 \mathrm{H}), 7.41(\mathrm{~d}, J=7.5 \mathrm{~Hz}, 1 \mathrm{H}), 7.28(\mathrm{~d}, J=$ $8.9 \mathrm{~Hz}, 2 \mathrm{H}), 7.23-7.14$ (m, 3H), 7.09 (d, J = $8.9 \mathrm{~Hz}, 2 \mathrm{H}), 7.00-6.93(\mathrm{~m}, 3 \mathrm{H}), 3.83(\mathrm{~s}, 3 \mathrm{H}), 3.61$ (s, 3H); ${ }^{13} \mathrm{C}$ NMR $\left(100 \mathrm{MHz}, \mathrm{CD}_{3} \mathrm{OD}\right) \delta 167.4,166.6,159.5,158.6,158.3,156.9,148.2,136.9,134.9$, 132.6, 131.0, 130.9, 130.5, 130.2, 129.2, 127.2, 123.3, 116.9, 116.7, 115.2, 115.0, 114.8, 101.7, 97.2, 54.5, 40.8; LRMS (EI) $m / z(\%) 451\left(\mathrm{M}^{+} ; 23\right), 406$ (100); HRMS (EI) for $\mathrm{C}_{28} \mathrm{H}_{21} \mathrm{NO}_{5}\left(\mathrm{M}^{+}\right)$: calcd 451.1420, Found: 451.1425.

\section{Synthesis of compound $\boldsymbol{8 b}$}

An oven-dried Schlenk tube was charged with $\mathrm{Pd}(\mathrm{OAc})_{2}(4 \mathrm{mg}, 0.02 \mathrm{mmol})$, BINAP (18 mg, $0.03 \mathrm{mmol})$ and $\mathrm{Cs}_{2} \mathrm{CO}_{3}(91 \mathrm{mg}, 0.28 \mathrm{mmol}$ ), and flushed with Ar gas for $5 \mathrm{~min}$. A solution of 6 (102 $\mathrm{mg}, 0.2 \mathrm{mmol}$ ) and 4-(methoxymethoxy)aniline $7 \mathbf{b}(37 \mathrm{mg}, 0.24 \mathrm{momol})$ in toluene $(2 \mathrm{~mL})$ was added, and the resulting mixture was first stirred under $\mathrm{Ar}$ at room temperature for $30 \mathrm{~min}$ and then at 100 ${ }^{\circ} \mathrm{C}$ for $20 \mathrm{~h}$. The reaction mixture was allowed to cool to room temperature, diluted with $\mathrm{CH}_{2} \mathrm{Cl}_{2}$ and filtered through a pad of Celite. The filter cake was washed with $\mathrm{CH}_{2} \mathrm{Cl}_{2}(3 \times 10 \mathrm{~mL})$. The filtrate was then concentrated and the residue was purified by silica gel column chromatography to give compound $8 \mathbf{b}\left(84 \mathrm{mg}, 82 \%\right.$ yield). ${ }^{1} \mathrm{H}$ NMR $\left(300 \mathrm{MHz}, \mathrm{CDCl}_{3}\right) \delta 7.99(\mathrm{~d}, J=7.4 \mathrm{~Hz}, 1 \mathrm{H}), 7.66-7.58(\mathrm{~m}, 2 \mathrm{H})$, $7.16(\mathrm{~d}, J=7.4 \mathrm{~Hz}, 1 \mathrm{H}), 7.08(\mathrm{~d}, J=8.9 \mathrm{~Hz}, 2 \mathrm{H}), 6.99(\mathrm{~d}, J=8.9 \mathrm{~Hz}, 2 \mathrm{H}), 6.91(\mathrm{~s}, 1 \mathrm{H}), 6.73(\mathrm{~s}, 1 \mathrm{H})$, 6.67 (s, 2H), $6.57-6.48(\mathrm{~m}, 2 \mathrm{H}), 5.94(\mathrm{~s}, \mathrm{br}, 1 \mathrm{H}), 5.16(\mathrm{~s}, 2 \mathrm{H}), 5.14(\mathrm{~s}, 2 \mathrm{H}), 3.48$ (s, 3H), 3.45 (s, 3H); ${ }^{13} \mathrm{C}$ NMR $\left(75.5 \mathrm{MHz}, \mathrm{CDCl}_{3}\right) \delta 169.6,158.8,153.5,153.1,152.6,152.5,147.6,135.3,134.9,129.6$, 129.1, 129.0, 127.0, 124.9, 124.0, 123.2, 117.4, 112.7, 112.6, 111.9, 109.0, 103.6, 100.8, 94.9, 94.3, 83.8, 56.1, 56.0; LRMS (EI) $m / z$ (\%) $511\left(\mathrm{M}^{+} ; 47\right), 467$ (100); HRMS (EI) for $\mathrm{C}_{30} \mathrm{H}_{25} \mathrm{NO}_{7}\left(\mathrm{M}^{+}\right)$: calcd 511.1631, Found: 511.1636.

\section{Synthesis of compound $\mathbf{9 b}$}

To a solution of $8 \mathbf{b}(84 \mathrm{mg}, 0.16 \mathrm{mmol})$ in THF $(4 \mathrm{~mL})$ at $0{ }^{\circ} \mathrm{C}$ was added $\mathrm{NaH}(10 \mathrm{mg}, 0.24$ $\mathrm{mmol}, 60 \%$ in mineral oil). The suspension was stirred for half an hour and then MeI ( $20 \mu \mathrm{L}, 0.32$ 
mmol) was introduced. The mixture was stirred at room temperature overnight and then quenched with water. The mixture was diluted with ethyl acetate, washed with $1 \mathrm{~N}$ hydrochloric acid and brine. After dried over anhydrous sodium sulfate the organic solution was concentrated in vacuo and the residue was purified by silica gel column chromatography to give compound $\mathbf{9 b}$ ( $64 \mathrm{mg}, 76 \%$ yield). ${ }^{1} \mathrm{H}$ NMR $\left(300 \mathrm{MHz}, \mathrm{CDCl}_{3}\right) \delta 7.98(\mathrm{~d}, J=7.2 \mathrm{~Hz}, 1 \mathrm{H}), 7.66-7.58(\mathrm{~m}, 2 \mathrm{H}), 7.15(\mathrm{~d}, J=7.2 \mathrm{~Hz}, 1 \mathrm{H})$, $7.14-7.08(\mathrm{~m}, 2 \mathrm{H}), 7.04(\mathrm{~d}, J=9.0 \mathrm{~Hz}, 2 \mathrm{H}), 6.92(\mathrm{~s}, 1 \mathrm{H}), 6.67(\mathrm{~s}, 1 \mathrm{H}), 6.52(\mathrm{~d}, J=9.0 \mathrm{~Hz}, 2 \mathrm{H}), 6.36$ - $6.34(\mathrm{~m}, 2 \mathrm{H}), 5.16(\mathrm{~s}, 4 \mathrm{H}), 3.48(\mathrm{~s}, 3 \mathrm{H}), 3.45$ (s, 3H), 3.25 (s, 3H); ${ }^{13} \mathrm{C} \mathrm{NMR}\left(75.5 \mathrm{MHz}, \mathrm{CDCl}_{3}\right) \delta$ 169.5, 158.7, 155.0, 153.1, 152.6, 152.4, 151.5, 141.7, 134.8, 129.5, 129.1, 128.4, 127.7, 127.1, 124.8, 124.0, 117.5, 112.8, 112.6, 110.9, 107.5, 103.6, 100.5, 94.6, 94.3, 83.8, 56.1, 56.0, 40.4; LRMS (EI) $\mathrm{m} / \mathrm{z}$ (\%) $525\left(\mathrm{M}^{+}\right.$; 52), 481 (78), 436 (100); HRMS (EI) for $\mathrm{C}_{31} \mathrm{H}_{27} \mathrm{NO}_{7}\left(\mathrm{M}^{+}\right)$: calcd 525.1788, Found: 525.1795 .

\section{Synthesis of compound 2}

To a solution of $9 \mathbf{b}(64 \mathrm{mg}, 0.12 \mathrm{mmol})$ in dry $\mathrm{CH}_{2} \mathrm{Cl}_{2}(2 \mathrm{~mL})$ was added trifluoroacetic acid $(2 \mathrm{~mL})$ dropwise at $0{ }^{\circ} \mathrm{C}$. The resulting solution was stirred at room temperature until TLC indicated all starting materials were consumed. The mixture was then concentrated in vacuo and azeotroped with toluene three times. The residue was dissolved in ethyl acetate and washed with saturated $\mathrm{NaHCO}_{3}$, followed by water and brine. The organic solution was concentrated in vacuo and then the residue was purified by silica gel column chromatography to give compound 2 (47 mg, 90\% yield). ${ }^{1} \mathrm{H}$ NMR (500 $\left.\mathrm{MHz}, \mathrm{CD}_{3} \mathrm{OD}\right) \delta 8.26(\mathrm{~d}, J=7.7 \mathrm{~Hz}, 1 \mathrm{H}), 7.83-7.75(\mathrm{~m}, 2 \mathrm{H}), 7.35(\mathrm{~d}, J=7.7 \mathrm{~Hz}, 1 \mathrm{H}), 7.13(\mathrm{~d}, J=$ $8.7 \mathrm{~Hz}, 2 \mathrm{H}), 7.09$ (d, J = 9.0 Hz, 1H), $7.04-7.02(\mathrm{~m}, 2 \mathrm{H}), 6.92-6.88(\mathrm{~m}, 4 \mathrm{H}), 6.80(\mathrm{~d}, J=9.4 \mathrm{~Hz}$, 1H), 3.52 (s, 3H); ${ }^{13} \mathrm{C}$ NMR (125.8 MHz, $\left.\mathrm{CD}_{3} \mathrm{OD}\right) \delta$ 169.1, 168.2, 159.3, 159.1, 158.7, 158.0, 139.2, 138.1, 134.6, 132.3, 132.1, 131.7, 131.6, 131.3, 130.1, 130.0, 128.9, 118.1, 118.0, 117.4, 115.9, 115.4, 103.6, 99.1, 42.3; LRMS (EI) $m / ₹(\%) 437\left(\mathrm{M}^{+}\right.$; 16), 392 (100); HRMS (EI) for $\mathrm{C}_{27} \mathrm{H}_{19} \mathrm{NO}_{5}\left(\mathrm{M}^{+}\right)$: calcd 437.1263, Found: 437.1266.

Scheme S3. Synthetic scheme for compounds 3-5 


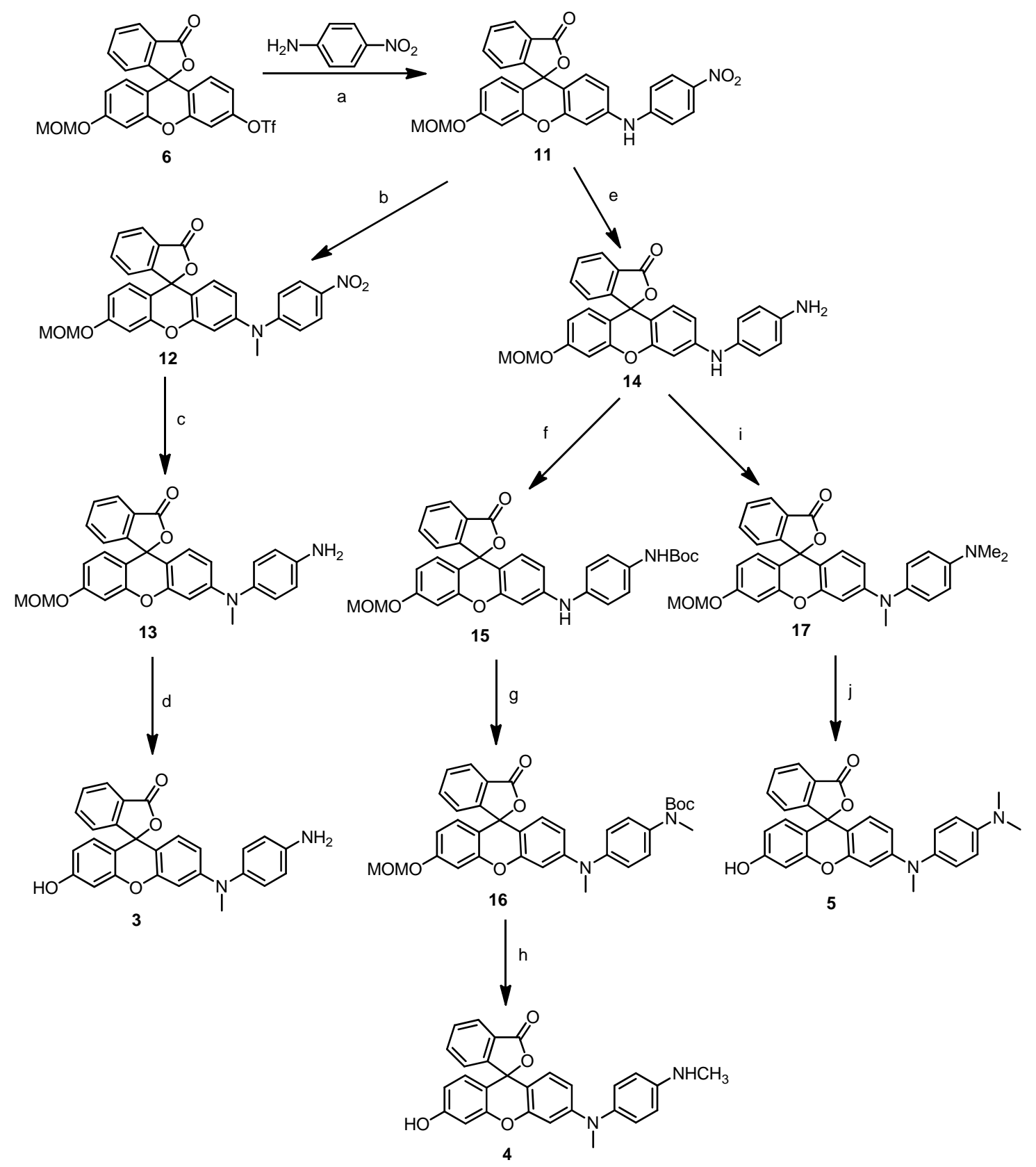

Reagents and Conditions: (a) $\mathrm{Pd}(\mathrm{OAc})_{2}, \mathrm{BINAP}, \mathrm{Cs}_{2} \mathrm{CO}_{3}$, toluene, $100{ }^{\circ} \mathrm{C}, 20 \mathrm{~h}, 80 \%$ yield; (b) $\mathrm{NaH}$, THF, MeI, 12 h, $83 \%$ yield; (c) Pd/C, $\mathrm{H}_{2}$, EtOH, 2 h, 77\%; (d) TFA, $\mathrm{CH}_{2} \mathrm{Cl}_{2}, 0^{\circ} \mathrm{C}$ to rt, $2 \mathrm{~h}, 91 \%$ yield; (e) $\mathrm{Pd} / \mathrm{C}, \mathrm{H}_{2}$, EtOH, 2 h, 74\%; (f) $\mathrm{Boc}_{2} \mathrm{O}, \mathrm{Et}_{3} \mathrm{~N}, \mathrm{DMAP}, \mathrm{CH}_{2} \mathrm{Cl}_{2}$, overnight, $96 \%$; (g) NaH, THF, MeI, $12 \mathrm{~h}, 67 \%$ yield; (h) TFA, $\mathrm{CH}_{2} \mathrm{Cl}_{2}, 0{ }^{\circ} \mathrm{C}$ to rt, $2 \mathrm{~h}, 88 \%$ yield; (i) NaH, THF, MeI, $12 \mathrm{~h}, 56 \%$ yield; (j) TFA, $\mathrm{CH}_{2} \mathrm{Cl}_{2}, 0{ }^{\circ} \mathrm{C}$ to rt, $2 \mathrm{~h}, 93 \%$ yield. 
Synthesis of compound 11

Compound 11 was synthesized from the coupling reaction between $\mathbf{6}$ and $p$-nitroaniline (1.2 equiv) in $80 \%$ yield according to a procedure reported previously. ${ }^{1}$ Characterization data of compound 11: ${ }^{1} \mathrm{H}$ NMR $\left(300 \mathrm{MHz} \mathrm{CDCl}_{3}\right) \delta 8.06-8.01(\mathrm{~m}, 3 \mathrm{H}), 7.72-7.63(\mathrm{~m}, 2 \mathrm{H}), 7.19(\mathrm{~d}, J=7.2 \mathrm{~Hz}, 1 \mathrm{H})$, $7.06-7.03$ (m, 3H), 6.93 (s, 1H), $6.80-6.64(\mathrm{~m}, 4 \mathrm{H}), 5.18$ (s, 2H), 3.46 (s, 3H); ${ }^{13} \mathrm{C}$ NMR $(75.5 \mathrm{MHz}$, $\left.\mathrm{CDCl}_{3}\right) \delta 169.8,159.0,152.8,152.2,148.8,142.6,140.3,135.4,130.0,129.1,129.0,126.5,126.0,125.1$, 124.0, 115.9, 115.1, 113.2, 112.0, 106.9, 103.7, 94.3, 83.4, 56.2; LRMS (EI) m/z (\%) $452\left(\mathrm{M}^{+}-\mathrm{CO}_{2}\right.$; 10), 136 (100); LRMS (FAB) m/ z (\%) $498\left(\mathrm{M}^{+}\right.$; 25), 154 (100); HRMS (EI) for $\mathrm{C}_{27} \mathrm{H}_{20} \mathrm{~N}_{2} \mathrm{O}_{5}\left(\mathrm{M}^{+}-\mathrm{CO}_{2}\right)$ : calcd 452.1372, Found: 452.1366.

\section{Synthesis of compound 12}

Compound 12 was synthesized from $N$-methylation of $\mathbf{1 1}$ in a similar procedure as the syntheses of $\mathbf{9 a}$ and $\mathbf{9 b}$. The yield for this transformation is $83 \%$. Characterization data of compound 12: ${ }^{1} \mathrm{H}$ NMR $\left(300 \mathrm{MHz}, \mathrm{CDCl}_{3}\right) \delta 8.10-8.04(\mathrm{~m}, 3 \mathrm{H}), 7.80-7.63(\mathrm{~m}, 2 \mathrm{H}), 7.24(\mathrm{~d}, J=7.4 \mathrm{~Hz}, 1 \mathrm{H})$, $7.14(\mathrm{~d}, J=2.0 \mathrm{~Hz}, 1 \mathrm{H}), 6.98(\mathrm{~d}, J=2.0 \mathrm{~Hz}, 1 \mathrm{H}), 6.90-6.82(\mathrm{~m}, 4 \mathrm{H}), 6.76-6.73(\mathrm{~m}, 2 \mathrm{H}), 5.20(\mathrm{~s}$, 2H), 3.48 (s, 3H), 3.44 (s, 3H); ${ }^{13} \mathrm{C}$ NMR (75.5 MHz, $\left.\mathrm{CDCl}_{3}\right) \delta$ 159.0, 153.0, 152.7, 152.4, 152.1, 148.5, 139.4, 135.2, 130.0, 129.6, 129.1, 126.6, 125.7, 125.2, 124.0, 120.8, 116.5, 114.5, 113.3 (2C), 112.1, 103.7, 94.4, 85.3, 56.2, 40.4; LRMS (EI) m/z (\%) $466\left(\mathrm{M}^{+}-\mathrm{CO}_{2} ; 11\right), 341$ (96), 267 (100); LRMS (FAB) m/z (\%) $511\left(\mathrm{M}^{+}\right.$; 38), 342 (60), 109 (100); HRMS (EI) for $\mathrm{C}_{28} \mathrm{H}_{22} \mathrm{~N}_{2} \mathrm{O}_{5}\left(\mathrm{M}^{+}-\mathrm{CO}_{2}\right)$ : calcd 466.1522, Found: 466.1529 .

Synthesis of compound 13

To a solution of $12(67 \mathrm{mg}, 0.13 \mathrm{mmol})$ in EtOH $(10 \mathrm{~mL})$ was slowly added palladium $(10 \%$ on activated carbon powder, $7 \mathrm{mg}$ ). The mixture was hydrogenated for 2 hours at room temperature. The mixture was then filtered through a pad of Celite, and the filtrate was concentrated in vacuo. The residue was purified by silica gel column chromatography to give compound 13 (48 mg, 77\% yield). ${ }^{1} \mathrm{H}$ NMR (300 MHz, $\left.\mathrm{CDCl}_{3}\right) \delta 7.99(\mathrm{~d}, J=7.5 \mathrm{~Hz}, 1 \mathrm{H}), 7.64-7.57(\mathrm{~m}, 2 \mathrm{H}), 7.17(\mathrm{~d}, J=7.5 \mathrm{~Hz}, 1 \mathrm{H}), 6.98$ $(\mathrm{d}, J=8.6 \mathrm{~Hz}, 2 \mathrm{H}), 6.91(\mathrm{~s}, 1 \mathrm{H}), 6.710-6.67(\mathrm{~m}, 4 \mathrm{H}), 6.51-6.48(\mathrm{~m}, 2 \mathrm{H}), 6.35-6.32(\mathrm{~m}, 1 \mathrm{H}), 5.18$ (s, 2H), 3.68 (br, 2H), 3.47 (s, 3H), 3.24 (s, 3H); ${ }^{13} \mathrm{C}$ NMR $\left(75.5 \mathrm{MHz}, \mathrm{CDCl}_{3}\right) \delta$ 169.6, 158.7, 153.2, 152.7, 152.4, 151.8, 144.5, 138.7, 134.7, 129.4, 129.1, 128.3, 128.0, 127.2, 124.8, 124.0, 116.2, 112.8, 112.5, 110.5, 106.8, 103.6, 99.8, 94.4, 84.0, 56.1, 40.4; LRMS (EI) m/z (\%) $480\left(\mathrm{M}^{+}\right.$; 68), 422 (100); HRMS (EI) for $\mathrm{C}_{29} \mathrm{H}_{24} \mathrm{~N}_{2} \mathrm{O}_{5}\left(\mathrm{M}^{+}\right)$: calcd 480.1685, Found: 480.1684 . 
Synthesis of compound $\mathbf{3}$

The compound $\mathbf{3}$ was synthesized by treatment of $\mathbf{1 3}$ with TFA as shown above. The compound 3 was obtained in 91\% yield. ${ }^{1} \mathrm{H}$ NMR $\left(400 \mathrm{MHz}, \mathrm{CD}_{3} \mathrm{OD}\right) \delta 8.02(\mathrm{~d}, J=7.2 \mathrm{~Hz}, 1 \mathrm{H}), 7.70$ $-7.64(\mathrm{~m}, 2 \mathrm{H}), 7.16(\mathrm{~d}, J=7.2 \mathrm{~Hz}, 1 \mathrm{H}), 6.92(\mathrm{~d}, J=8.6 \mathrm{~Hz}, 2 \mathrm{H}), 6.76(\mathrm{~d}, J=8.6 \mathrm{~Hz}, 2 \mathrm{H}), 6.69(\mathrm{~d}, J=$ $8.8 \mathrm{~Hz}, 1 \mathrm{H}), 6.64(\mathrm{~d}, J=2.2 \mathrm{~Hz}, 1 \mathrm{H}), 6.59-6.52(\mathrm{~m}, 3 \mathrm{H}), 6.42(\mathrm{dd}, J=8.8,2.2 \mathrm{~Hz}, 1 \mathrm{H}), 3.26(\mathrm{~s}, 3 \mathrm{H})$; ${ }^{13} \mathrm{C}$ NMR $\left(100 \mathrm{MHz}, \mathrm{CD}_{3} \mathrm{OD}\right) \delta$ 164.6, 154.5, 153.7, 153.6, 153.5, 147.5, 146.2, 137.3, 133.7, 129.5, 129.4, 128.5, 127.6, 127.3, 125.9, 125.4, 116.1, 114.6, 114.1, 111.4, 108.5, 102.3, 98.6, 76.0, 39.7; LRMS (EI) $m / z(\%) 436\left(\mathrm{M}^{+} ; 36\right), 390$ (100); HRMS (EI) for $\mathrm{C}_{27} \mathrm{H}_{20} \mathrm{~N}_{2} \mathrm{O}_{4}\left(\mathrm{M}^{+}\right)$: calcd 436.1423, Found: 436.1423 .

\section{Synthesis of compound 14}

To a solution of $\mathbf{1 1}(200 \mathrm{mg}, 0.40 \mathrm{mmol})$ in EtOH $(20 \mathrm{~mL})$ was slowly added palladium (10\% on activated carbon powder, $20 \mathrm{mg}$ ). The mixture was hydrogenated for 2 hours at room temperature. The mixture was then filtered through a pad of Celite, and the filtrate was concentrated in vacuo. The residue was purified by silica gel column chromatography to give compound 14 (138 $\mathrm{mg}$, 74\% yield). ${ }^{1} \mathrm{H}$ NMR $\left(400 \mathrm{MHz}, \mathrm{CDCl}_{3}\right) \delta 7.99(\mathrm{~d}, J=7.3 \mathrm{~Hz}, 1 \mathrm{H}), 7.64-7.57(\mathrm{~m}, 2 \mathrm{H}), 7.16(\mathrm{~d}, J=7.3 \mathrm{~Hz}, 1 \mathrm{H})$, $6.96(\mathrm{~d}, J=8.6 \mathrm{~Hz}, 2 \mathrm{H}), 6.89(\mathrm{~d}, J=1.3 \mathrm{~Hz}, 1 \mathrm{H}), 6.710-6.67(\mathrm{~m}, 4 \mathrm{H}), 6.51-6.48(\mathrm{~m}, 2 \mathrm{H}), 6.35-$ $6.32(\mathrm{~m}, 1 \mathrm{H}), 5.18(\mathrm{~s}, 2 \mathrm{H}), 3.68(\mathrm{br}, 2 \mathrm{H}), 3.47(\mathrm{~s}, 3 \mathrm{H}), 3.24$ (s, 3H); ${ }^{13} \mathrm{C} \mathrm{NMR}\left(75.5 \mathrm{MHz}, \mathrm{CDCl}_{3}\right) \delta$ 169.6, 158.7, 153.2, 152.7, 152.4, 151.8, 144.5, 138.7, 134.7, 129.4, 129.1, 128.3, 128.0, 127.2, 124.8, 124.0, 116.2, 112.8, 112.5, 110.5, 106.8, 103.6, 99.8, 94.4, 84.0, 56.1, 40.4; LRMS (EI) $m / z . \%) 466\left(\mathrm{M}^{+}\right.$; 70), 422 (100); HRMS (EI) for $\mathrm{C}_{28} \mathrm{H}_{22} \mathrm{~N}_{2} \mathrm{O}_{5}\left(\mathrm{M}^{+}\right)$: calcd 466.1529, Found: 466.1521.

\section{Synthesis of compound 15}

To a solution of $14(90 \mathrm{mg}, 0.19 \mathrm{mmol})$ in dry $\mathrm{CH}_{2} \mathrm{Cl}_{2}(5 \mathrm{~mL})$ were added $\mathrm{Et}_{3} \mathrm{~N}(30 \mu \mathrm{L}, 0.21$ mmol), DMAP ( $5 \mathrm{mg}, 0.04 \mathrm{mmol}$ ), and $\mathrm{Boc}_{2} \mathrm{O}(50 \mu \mathrm{L}, 0.21 \mathrm{mmol})$ successively at room temperature. The reaction mixture was stirred overnight and then diluted with $\mathrm{CH}_{2} \mathrm{Cl}_{2}(30 \mathrm{~mL})$. The resulting solution was washed with saturated $\mathrm{NaHCO}_{3}$ solution followed by $0.1 \mathrm{~N} \mathrm{HCl}$ and brine. The organic layer was dried over anhydrous sodium sulfate, concentrated and purified by silica gel column chromatography to give compound 15 (103 mg, 96\% yield). ${ }^{1} \mathrm{H}$ NMR (400 MHz, $\left.\mathrm{CDCl}_{3}\right) \delta 7.99$ (d, $J$ $=7.4 \mathrm{~Hz}, 1 \mathrm{H}), 7.66-7.57(\mathrm{~m}, 2 \mathrm{H}), 7.30(\mathrm{~d}, J=8.8 \mathrm{~Hz}, 2 \mathrm{H}), 7.16(\mathrm{~d}, J=7.4 \mathrm{~Hz}, 1 \mathrm{H}), 7.05(\mathrm{~d}, J=8.8$ $\mathrm{Hz}, 2 \mathrm{H}), 6.91(\mathrm{~d}, J=2.0 \mathrm{~Hz}, 1 \mathrm{H}), 6.76(\mathrm{~d}, J=2.0 \mathrm{~Hz}, 1 \mathrm{H}), 6.70-6.65(\mathrm{~m}, 2 \mathrm{H}), 6.61(\mathrm{br}, 1 \mathrm{H}), 6.57-$ $6.51(\mathrm{~m}, 2 \mathrm{H}), 5.98(\mathrm{br}, 1 \mathrm{H}), 5.17(\mathrm{~s}, 2 \mathrm{H}), 3.46(\mathrm{~s}, 3 \mathrm{H}), 1.51(\mathrm{~s}, 9 \mathrm{H}) ;{ }^{13} \mathrm{C}$ NMR $\left(100 \mathrm{MHz}, \mathrm{CDCl}_{3}\right) \delta$ 169.6, 158.7, 153.1, 153.0, 152.5, 147.0, 136.4, 134.9, 133.8, 129.6, 129.0, 128.9, 126.9, 124.9, 124.0, 
121.8, 120.1, 112.7, 112.6, 112.2, 109.3, 106.8, 103.6, 101.3, 94.3, 83.7, 80.4, 56.1, 28.4; LRMS (EI) $\mathrm{m} / \mathrm{z}$ (\%) $466\left([\mathrm{M}+\mathrm{H}]^{+}-\right.$Boc, 8), 153 (60); HRMS (EI) for $\mathrm{C}_{28} \mathrm{H}_{22} \mathrm{~N}_{2} \mathrm{O}_{5}\left([\mathrm{M}+\mathrm{H}]^{+}-\right.$Boc): calcd 466.1529, Found: 466.1530 .

\section{Synthesis of compound 16}

To a solution of $15(103 \mathrm{mg}, 0.18 \mathrm{mmol})$ in THF $(4 \mathrm{~mL})$ at $0{ }^{\circ} \mathrm{C}$ was added $\mathrm{NaH}(16 \mathrm{mg}$, $0.40 \mathrm{mmol}, 60 \%$ in mineral oil). The suspension was stirred for half an hour and then $\mathrm{MeI}(34 \mu \mathrm{L}, 0.54$ mmol) was introduced. The mixture was stirred at room temperature overnight and then quenched with water. The mixture was diluted with ethyl acetate $(30 \mathrm{~mL})$, washed with $1 \mathrm{~N}$ hydrochloric acid and brine. After dried over anhydrous sodium sulfate the organic solution was concentrated in vacuo and the residue was purified by silica gel column chromatography to give compound 16 ( $72 \mathrm{mg}, 67 \%$ yield). ${ }^{1} \mathrm{H}$ NMR $\left(400 \mathrm{MHz}, \mathrm{CDCl}_{3}\right) 88.00(\mathrm{~d}, J=7.4 \mathrm{~Hz}, 1 \mathrm{H}), 7.67-7.57(\mathrm{~m}, 2 \mathrm{H}), 7.23(\mathrm{~d}, J=8.4 \mathrm{~Hz}, 2 \mathrm{H})$, $7.18(\mathrm{~d}, J=7.4 \mathrm{~Hz}, 1 \mathrm{H}), 7.13(\mathrm{~d}, J=8.4 \mathrm{~Hz}, 2 \mathrm{H}), 6.93(\mathrm{~s}, 1 \mathrm{H}), 6.71-6.64(\mathrm{~m}, 3 \mathrm{H}), 6.55(\mathrm{~d}, J=8.8 \mathrm{~Hz}$, $1 \mathrm{H}), 6.49(\mathrm{~d}, J=8.8 \mathrm{~Hz}, 1 \mathrm{H}), 5.18(\mathrm{~s}, 2 \mathrm{H}), 3.46(\mathrm{~s}, 3 \mathrm{H}), 3.31(\mathrm{~s}, 3 \mathrm{H}), 3.26(\mathrm{~s}, 3 \mathrm{H}), 1.47(\mathrm{~s}, 9 \mathrm{H}) ;{ }^{13} \mathrm{C}$ NMR $\left(100 \mathrm{MHz}, \mathrm{CDCl}_{3}\right) \delta$ 169.6, 158.7, 154.8, 153.1, 152.6, 152.4, 150.9, 144.8, 140.4, 134.8, 129.5, 129.1, 128.4, 127.0, 126.6, 125.3, 124.9, 124.0, 112.7, 112.6, 112.2, 108.6, 103.6, 102.1, 94.3, 83.6, 80.4, 56.1, 40.2, 37.3, 28.3; LRMS (EI) m/ ₹ (\%) 595 ([M+H]+; 20), 539 (14), 495 (100); HRMS (EI) for $\mathrm{C}_{35} \mathrm{H}_{34} \mathrm{~N}_{2} \mathrm{O}_{7}\left(\mathrm{M}^{+}\right)$: calcd 594.2366, Found: 594.2361.

\section{Synthesis of compound 4}

The compound 4 was synthesized by treatment of 16 with TFA as shown above. The compound 4 was obtained in $88 \%$ yield. ${ }^{1} \mathrm{H}$ NMR $\left(500 \mathrm{MHz}, \mathrm{CDCl}_{3}\right) \delta 8.05(\mathrm{~s}, 1 \mathrm{H}), 7.56(\mathrm{~s}, 2 \mathrm{H}), 7.11$ $(\mathrm{s}, 1 \mathrm{H}), 6.92(\mathrm{~s}, 2 \mathrm{H}), 6.73-6.68(\mathrm{~m}, 3 \mathrm{H}), 6.59-6.41(\mathrm{~m}, 5 \mathrm{H}), 3.24(\mathrm{~s}, 3 \mathrm{H}), 2.82(\mathrm{~s}, 3 \mathrm{H}) ;{ }^{13} \mathrm{C}$ NMR $\left(125.8 \mathrm{MHz}, \mathrm{CDCl}_{3}\right) \delta$ 170.0, 163.2, 154.4, 153.9, 147.8, 146.3, 136.4, 133.1, 130.7, 129.8, 129.5, 129.3, 127.7, 127.4, 126.8, 125.8, 114.8, 113.5, 112.2, 109.7, 102.9, 98.9, 40.8, 30.9; LRMS (EI) $\mathrm{m} / \mathrm{z}$.\%) 450 ( $\left.\mathrm{M}^{+} ; 30\right)$, 405 (100); HRMS (EI) for $\mathrm{C}_{28} \mathrm{H}_{22} \mathrm{~N}_{2} \mathrm{O}_{4}\left(\mathrm{M}^{+}\right)$: calcd 450.1580, Found: 450.1584.

\section{Synthesis of compound 17}

To a solution of $14(52 \mathrm{mg}, 0.11 \mathrm{mmol})$ in THF $(3 \mathrm{~mL})$ at $0{ }^{\circ} \mathrm{C}$ was added $\mathrm{NaH}(18 \mathrm{mg}, 0.44$ $\mathrm{mmol}, 60 \%$ in mineral oil). The suspension was stirred for half an hour and then MeI (28 $\mu \mathrm{L}, 0.44$ $\mathrm{mmol}$ ) was introduced. The mixture was stirred at room temperature overnight and then quenched with water. The mixture was diluted with ethyl acetate $(20 \mathrm{~mL})$, washed with $1 \mathrm{~N}$ hydrochloric acid and brine. After dried over anhydrous sodium sulfate the organic solution was concentrated in vacuo and 
the residue was purified by silica gel column chromatography to give compound 17 (31 mg, 56\% yield). ${ }^{1} \mathrm{H}$ NMR $\left(400 \mathrm{MHz}, \mathrm{CDCl}_{3}\right) \delta 7.99(\mathrm{~d}, J=7.4 \mathrm{~Hz}, 1 \mathrm{H}), 7.65-7.56(\mathrm{~m}, 2 \mathrm{H}), 7.17(\mathrm{~d}, J=7.4 \mathrm{~Hz}, 1 \mathrm{H})$, $7.06(\mathrm{~d}, J=8.9 \mathrm{~Hz}, 2 \mathrm{H}), 6.91(\mathrm{~s}, 1 \mathrm{H}), 6.74(\mathrm{~d}, J=8.9 \mathrm{~Hz}, 2 \mathrm{H}), 6.67(\mathrm{~s}, 2 \mathrm{H}), 6.51-6.48(\mathrm{~m}, 2 \mathrm{H}), 6.35$ - $6.33(\mathrm{~m}, 1 \mathrm{H}), 5.18$ (s, 2H), 3.47 (s, 3H), 3.26 (s, 3H), 2.96 (s, 6H); ${ }^{13} \mathrm{C}$ NMR $\left(100 \mathrm{MHz}, \mathrm{CDCl}_{3}\right) \delta$ 169.6, 158.6, 153.2, 152.7, 152.4, 152.0, 148.8, 136.9, 134.7, 129.4, 129.1, 128.3, 127.7, 127.1, 124.8, 124.0, 113.5, 112.8, 112.4, 110.4, 106.6, 103.6, 99.6, 94.3, 84.1, 56.1, 40.7, 40.4; LRMS (EI) $\mathrm{m} / \mathrm{z}$ (\%) $509\left([\mathrm{M}+\mathrm{H}]^{+} ; 100\right)$; HRMS (EI) for $\mathrm{C}_{31} \mathrm{H}_{28} \mathrm{~N}_{2} \mathrm{O}_{5}$ : calcd 508.1998, Found: 508.2000.

\section{Synthesis of compound $\mathbf{5}$}

The compound $\mathbf{5}$ was synthesized by treatment of $\mathbf{1 7}$ with TFA as shown above. The compound 5 was obtained in $93 \%$ yield. ${ }^{1} \mathrm{H}$ NMR $\left(400 \mathrm{MHz}, \mathrm{CDCl}_{3}\right) \delta 8.04(\mathrm{~d}, J=7.1 \mathrm{~Hz}, 1 \mathrm{H}), 7.60$ $-7.54(\mathrm{~m}, 2 \mathrm{H}), 7.13(\mathrm{~d}, J=7.1 \mathrm{~Hz}, 1 \mathrm{H}), 7.03(\mathrm{~d}, J=8.6 \mathrm{~Hz}, 2 \mathrm{H}), 6.72(\mathrm{~d}, J=8.6 \mathrm{~Hz}, 2 \mathrm{H}), 6.69-6.63$ $(\mathrm{m}, 3 \mathrm{H}), 6.40(\mathrm{~s}, 2 \mathrm{H}), 6.39$ (d, J = 9.3 Hz, 1H), $3.60(\mathrm{br}, 3 \mathrm{H}), 3.26(\mathrm{~s}, 3 \mathrm{H}), 2.96(\mathrm{~s}, 6 \mathrm{H}) ;{ }^{13} \mathrm{C}$ NMR $(100$ $\left.\mathrm{MHz}, \mathrm{CDCl}_{3}\right) \delta$ 170.1, 162.5, 154.1, 153.8, 153.2, 149.0, 147.8, 136.1, 133.4, 130.0, 129.7, 129.4, 129.0, 127.6, 126.2, 125.3, 114.2, 113.5, 112.1, 111.6, 108.7, 103.0, 99.1, 40.7, 40.6; LRMS (EI) $\mathrm{m} / \mathrm{z}(\%) 464$ ( $\mathrm{M}^{+}$; 35), 419 (100); HRMS (EI) for $\mathrm{C}_{29} \mathrm{H}_{24} \mathrm{~N}_{2} \mathrm{O}_{4}\left(\mathrm{M}^{+}\right)$: calcd 464.1736, Found: 464.1738.

Scheme S4. Synthesis of $N$-methylrhodol

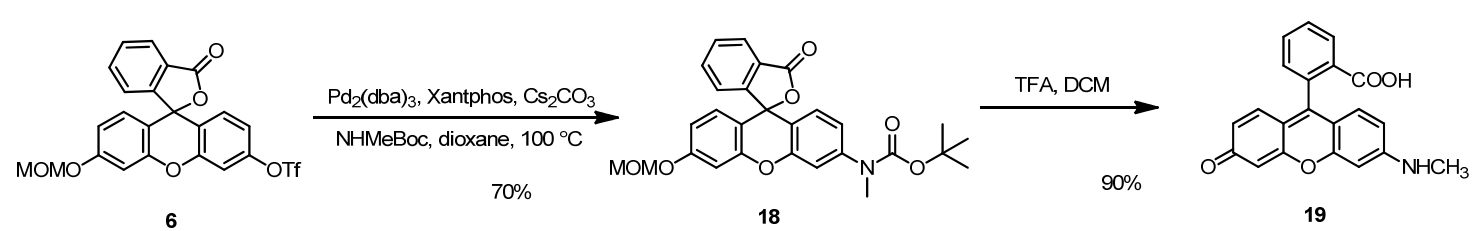

Synthesis of compound 18

An oven-dried Schlenk tube was charged with $\mathrm{Pd}_{2}(\mathrm{dba})_{3}(26 \mathrm{mg}, 0.029 \mathrm{mmol})$, Xantphos (33 $\mathrm{mg}, 0.06 \mathrm{mmol})$ and $\mathrm{Cs}_{2} \mathrm{CO}_{3}(113 \mathrm{mg}, 0.35 \mathrm{mmol})$, and flushed with Ar gas for $5 \mathrm{~min}$. A solution of 6 $(145 \mathrm{mg}, 0.29 \mathrm{mmol})$ and $t$-butyl $N$-methylcarbamate $(75 \mathrm{mg}, 0.57 \mathrm{momol})$ in dioxane $(3 \mathrm{~mL})$ was added, and the resulting mixture was first stirred under $\mathrm{Ar}$ at room temperature for $30 \mathrm{~min}$ and then at $100{ }^{\circ} \mathrm{C}$ for $20 \mathrm{~h}$. The reaction mixture was allowed to cool to room temperature, diluted with $\mathrm{CH}_{2} \mathrm{Cl}_{2}$ and filtered through a pad of Celite. The filter cake was washed with $\mathrm{CH}_{2} \mathrm{Cl}_{2}(3 \times 10 \mathrm{~mL})$. The filtrate was then concentrated and the residue was purified by silica gel column chromatography to give compound 18 (98 mg, $0.21 \mathrm{mmol}, 70 \%$ yield). ${ }^{1} \mathrm{H}$ NMR (400 MHz, $\left.\mathrm{CDCl}_{3}\right) \delta 8.03(\mathrm{~d}, J=7.2 \mathrm{~Hz}, 1 \mathrm{H})$, $7.70-7.59(\mathrm{~m}, 2 \mathrm{H}), 7.21(\mathrm{~d}, J=2.1 \mathrm{~Hz}, 1 \mathrm{H}), 7.17(\mathrm{~d}, J=7.2 \mathrm{~Hz}, 1 \mathrm{H}), 7.00-6.93(\mathrm{~m}, 2 \mathrm{H}), 6.76-6.69$ 
(m, 3H), 5.20 (s, 2H), 3.48 (s, 3H), 3.28 (s, 3H), $1.48(\mathrm{~s}, 9 \mathrm{H}) ;{ }^{13} \mathrm{C}$ NMR (101 MHz, $\left.\mathrm{CDCl}_{3}\right) \delta$ 169.46, 159.02, 154.35, 153.16, 152.37, 151.39, 145.83, 135.14, 129.89, 129.16, 128.49, 128.04, 126.65, 125.16, 124.09, 120.69, 115.55, 113.11, 112.32, 103.75, 94.44, 82.68, 81.16, 56.29, 37.08, 28.40; LRMS (EI) $\mathrm{m} / \mathrm{z}$ (\%): 489 (M+, 2), 445 (13), 389 (61); HRMS (EI): calcd for $\mathrm{C}_{28} \mathrm{H}_{27} \mathrm{NO}_{7}\left(\mathrm{M}^{+}\right)$, 489.1782; found, 489.1779.

\section{Synthesis of compound 19}

To a solution of $18(75 \mathrm{mg}, 0.15 \mathrm{mmol})$ in dry $\mathrm{CH}_{2} \mathrm{Cl}_{2}(2 \mathrm{~mL})$ was added TFA $(2 \mathrm{~mL})$ dropwise at $0{ }^{\circ} \mathrm{C}$. The resulting solution was stirred at room temperature for $2 \mathrm{hr}$. The mixture was concentrated in vacuo and then diluted with saturated $\mathrm{NaHCO}_{3}$ solution. The mixture was extracted with chloroform containing 10\% isopropanol three times. The organic layers were combined and dried over anhydrous sodium sulfate. The organic solution was concentrated and purified by silica gel column chromatography to give the product $N$-methylrhodol 19 (59 mg, 90\% yield). ${ }^{1} \mathrm{H}$ NMR (400 MHz, $\left.\mathrm{CD}_{3} \mathrm{OD}\right) \delta 8.22(\mathrm{~d}, J=7.4 \mathrm{~Hz}, 1 \mathrm{H}), 7.82-7.73(\mathrm{~m}, 2 \mathrm{H}), 7.33(\mathrm{~d}, J=7.4 \mathrm{~Hz}, 1 \mathrm{H}), 7.04(\mathrm{~d}, J=9.0 \mathrm{~Hz}$, 1H), $6.99-6.94(\mathrm{~m}, 2 \mathrm{H}), 6.82(\mathrm{dd}, J=9.0,2.3 \mathrm{~Hz}, 1 \mathrm{H}), 6.77-6.74(\mathrm{~m}, 2 \mathrm{H}), 3.01(\mathrm{~s}, 3 \mathrm{H}) ;{ }^{13} \mathrm{C}$ NMR $\left(101 \mathrm{MHz}, \mathrm{CD}_{3} \mathrm{OD}\right) \delta 170.20,168.12,168.10,159.65,159.41,157.53,134.26,132.84,132.08,131.96$, 131.47, 131.39, 130.62, 129.69, 117.75, 117.23, 115.27, 114.38, 103.61, 96.42, 30.50; LRMS (EI) $\mathrm{m} / \mathrm{z}$ $(\%): 301\left(\mathrm{M}^{+}-\mathrm{CO}_{2}, 23\right), 272$ (11); HRMS (EI): calcd for $\mathrm{C}_{20} \mathrm{H}_{15} \mathrm{NO}_{2}\left(\mathrm{M}^{+}-\mathrm{CO}_{2}\right), 301.1097$; found, 301.1082 .

Scheme S5. Synthesis of probe HKGreen-4A

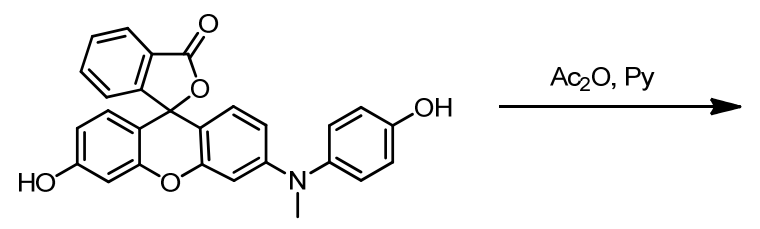

2, HKGreen-4

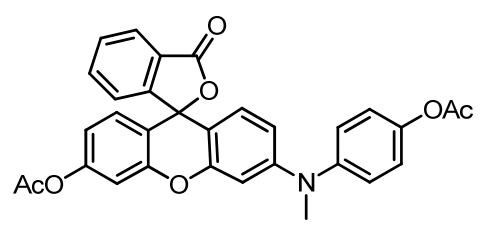

HKGreen-4A

To a solution of $2(53 \mathrm{mg}, 0.39 \mathrm{mmol})$ in pyridine $(2 \mathrm{~mL})$ was added acetic anhydride $(1 \mathrm{~mL})$. The resulting mixture was heated to reflux for 2 hours. Then the reaction mixture was quenched with water and diluted with ethyl acetate. The organic solution was washed with saturated $\mathrm{NaHCO}_{3}$ and brine, dried over anhydrous sodium sulfate and concentrated. The residue was purified by silica gel column chromatography to give HKGreen-4A (46 mg, 73\% yield). ${ }^{1} \mathrm{H}$ NMR (300 $\left.\mathrm{MHz}, \mathrm{CDCl}_{3}\right) \delta$ $7.99(\mathrm{~d}, J=7.3 \mathrm{~Hz}, 1 \mathrm{H}), 7.69-7.55(\mathrm{~m}, 2 \mathrm{H}), 7.20-7.16(\mathrm{~m}, 3 \mathrm{H}), 7.14-7.04(\mathrm{~m}, 3 \mathrm{H}), 6.82-6.72(\mathrm{~m}$, $2 \mathrm{H}), 6.66(\mathrm{~d}, J=2.2 \mathrm{~Hz}, 1 \mathrm{H}), 6.56(\mathrm{~d}, J=8.8 \mathrm{~Hz}, 1 \mathrm{H}), 6.48(\mathrm{dd}, J=8.8,2.2 \mathrm{~Hz}, 1 \mathrm{H}), 3.29(\mathrm{~s}, 3 \mathrm{H}), 2.28$ (s, 6H); ${ }^{13} \mathrm{C} \mathrm{NMR}\left(75 \mathrm{MHz}, \mathrm{CDCl}_{3}\right) \delta 169.37,169.21,168.76,152.73,152.03,151.96,151.71,150.84$, 
147.34, 145.03, 134.91, 129.66, 128.89, 128.35, 126.61, 126.13, 124.84, 123.92, 122.65, 117.07, 116.78, 112.24, 110.10, 108.20, 101.87, 82.82, 40.21, 20.97; LRMS (EI) $m / z(\%): 522\left(\mathrm{M}^{+}, 25\right), 478$ (100); HRMS (EI): calcd for $\mathrm{C}_{31} \mathrm{H}_{23} \mathrm{NO}_{7}\left(\mathrm{M}^{+}\right)$, 521.1475; found, 521.1480 .

\section{General Protocols for Photophysical Characterization of Probes}

The compounds $\mathbf{1} \mathbf{- 5}$ were dissolved in DMF to make $10 \mathrm{mM}$ or $1 \mathrm{mM}$ stock solutions, which were diluted 1000 times to $10 \mu \mathrm{M}$ or $1 \mu \mathrm{M}$ as testing solutions with $0.1 \mathrm{mM}$ phosphate buffer $(0.1 \mathrm{M}$, $\mathrm{pH}$ 7.4). The absorbance and fluorescence spectra of probe testing solutions were recorded under a CARY 50 Bio UV-Visible spectrophotometer and a Hitachi F-2500 fluorescence spectrophotometer, respectively. For the fluorescence spectra, slit widths were set at $2.5 \mathrm{~nm}$ for both excitation and emission spectra, and the photomultiplier voltage was $700 \mathrm{~V}$.

To test the fluorescence responses of probes toward various ROS and RNS, aliquots of ROS or RNS solutions were slowly added to the testing solutions of probes (each $5 \mathrm{~mL}$ ) with vigorously stirring at room temperature in the dark. The volume changes after addition of ROS or RNS solutions were less than $1 \%$. The fluorescence intensities of the testing solutions were measured after $30 \mathrm{~min}$ or $1 \mathrm{~h}$.

To determine the quantum yields, probe or fluorophore stock solutions ( 2 and 19) were prepared by accurately weighing and dissolving the samples in $\mathrm{CH}_{3} \mathrm{CN}$ (HPLC grade). Testing solutions for measuring UV absorbance and fluorescence were prepared by further dilution of the stock solutions with $50 \mathrm{mM}$ potassium phosphate buffer at $\mathrm{pH}$ 8.0. The quantum yields of the fluorophores were estimated by comparison of the integrated area of the corrected emission spectrum of the sample with that of a reference solution, i.e., a solution of fluorescein in $0.1 \mathrm{M} \mathrm{NaOH}$ solution $(\Phi=0.95)$. The quantum yield of a sample was related to that of the reference, and determined by the equation

$$
\Phi_{\text {sample }}=\left(\frac{A_{\text {reference }}}{A_{\text {sample }}}\right)\left(\frac{F_{\text {sample }}}{F_{\text {reference }}}\right) \Phi_{\text {reference }}(1)
$$

wherein $\Phi$ is the fluorescence quantum yield, A is the absorbance at the excitation wavelength, $\mathrm{F}$ is the area under the emission curve. The concentration of the reference was adjusted to match the absorbance of the test sample at the wavelength of excitation so that the absorbance ratio is equal to 1. 
Sources for different ROS/RNS are described as follows. ROO ${ }^{\bullet}$ was generated from 2,2'Azobis(2-amidinopropane)dihydrochloride, which was firstly dissolved in deionizer water and then added into the probe testing solutions at $37^{\circ} \mathrm{C}$ for $1 \mathrm{~h} .{ }^{1} \mathrm{O}_{2}$ (singlet oxygen) was generated from 3,3'(naphthalene-1,4-diyl)dipropionic acid. $\mathrm{H}_{2} \mathrm{O}_{2}$ solution was added directly. The stock $\mathrm{H}_{2} \mathrm{O}_{2}$ solution was purchased from Sigma-Aldrich. The concentration of $\mathrm{H}_{2} \mathrm{O}_{2}$ was determined by iodometric titration prior to use. ${ }^{N} \mathrm{NO}$ was generated from SNP (Sodium Nitroferricyanide (III) Dihydrate). The experiments were performed under anaerobic conditions. Deionizer water was degassed with $\mathrm{Ar}$ for $20 \mathrm{~min}$. SNP was added into degassed deionizer water under Ar atmosphere then stirred for $30 \mathrm{~min}$ at $25^{\circ} \mathrm{C}$. The probe solution was also degassed before the reaction with SNP. Superoxide $\left(\mathrm{O}_{2}{ }^{--}\right)$was generated from xanthine/xanthine oxidase system. Xanthine oxidase was added first. After xanthine oxidase was dissolved, xanthine in $1.6 \mathrm{M} \mathrm{NaOH}$ was then added. The mixtures were stirred at $25{ }^{\circ} \mathrm{C}$ for $1 \mathrm{~h}$. The source of $\mathrm{NaOCl}$ was commercial bleach. The concentration of $\mathrm{OCl}^{-}$was determined by titration with $\mathrm{S}_{2} \mathrm{O}_{3}{ }^{2-}$. Hydroxyl radical $\left({ }^{\circ} \mathrm{OH}\right)$ was generated by Fenton reaction. To generate ${ }^{\bullet} \mathrm{OH}$, ferrous chloride was added in the presence of 10 equiv of $\mathrm{H}_{2} \mathrm{O}_{2}$. The concentration of ${ }^{\bullet} \mathrm{OH}$ was equal to the $\mathrm{Fe}(\mathrm{II})$ concentration. Nitrogen dioxide $\left(\mathrm{NO}_{2}\right)$ was purchased from Aldrich and introduced into the probe solution via a gas tight syringe. ${ }^{2}$ Carbonate radical $\left(\mathrm{CO}_{3}{ }^{--}\right)$was generated by the $\mathrm{SOD} 1 / \mathrm{H}_{2} \mathrm{O}_{2} /$ bicarbonate system. ${ }^{3}$ Peroxynitrite $\left(\mathrm{ONOO}^{-}\right)$solution was synthesized according to literature report. Briefly, a mixture of sodium nitrite $(0.6 \mathrm{M})$ and hydrogen peroxide $(0.7 \mathrm{M})$ was acidified with hydrochloric acid $(0.6 \mathrm{M})$, and sodium hydroxide $(1.5 \mathrm{M})$ was added within 1-2 s to make the solution alkaline. The excess hydrogen peroxide was removed by passing the solution through a short column of manganese dioxide. The resulting solution was split into small aliquots and stored at lower than $-18^{\circ} \mathrm{C}$. The aliquots were thawed immediately before use, and the concentration of peroxynitrite was determined by measuring the absorption of the solution at $302 \mathrm{~nm}$. The extinction coefficient of peroxynitrite solution in $0.1 \mathrm{M} \mathrm{NaOH}$ is $1670 \mathrm{M}^{-1} \mathrm{~cm}^{-1}$ at $302 \mathrm{~nm}$. CONOO- $=\mathrm{Abs}_{302 \mathrm{~nm}}$ / 1.67 (mM).

\section{Probe Screening}

The responses of compound 1 and compound 2 (HKGreen-4) toward peroxynitrite are compared in Figure S1. Compound $\mathbf{1}$ shows a much weaker fluorescence increase toward peroxynitrite than compound $\mathbf{2}$. Different reactivity of compounds $\mathbf{2} \mathbf{- 5}$ toward peroxynitrite and hypochlorous acid is summarized in Figure S2. Among these compounds, compound 2 shows good selectivity toward peroxynitrite over hypochlorous acid, while compounds 3-5 exhibit strong fluorescence responses toward both hypochlorous acid and peroxynitrite. 


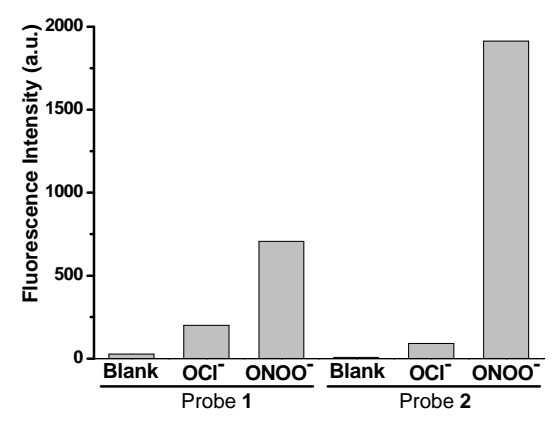

Figure S1. Fluorescence increases of compound $1(10 \mu \mathrm{M}$ in $0.1 \mathrm{M}$ phosphate buffer at pH 7.4) and compound $2(1 \mu \mathrm{M}$ in $0.1 \mathrm{M}$ phosphate buffer at $\mathrm{pH} 7.4)$ toward hypochlorous acid and peroxynitrite. Hypochlorous acid and peroxynitrite were both added in 1 equiv relative to compounds 1 and $\mathbf{2}$. For both compounds the fluorescence intensities were recorded at $535 \mathrm{~nm}$ with excitation at $517 \mathrm{~nm}$.
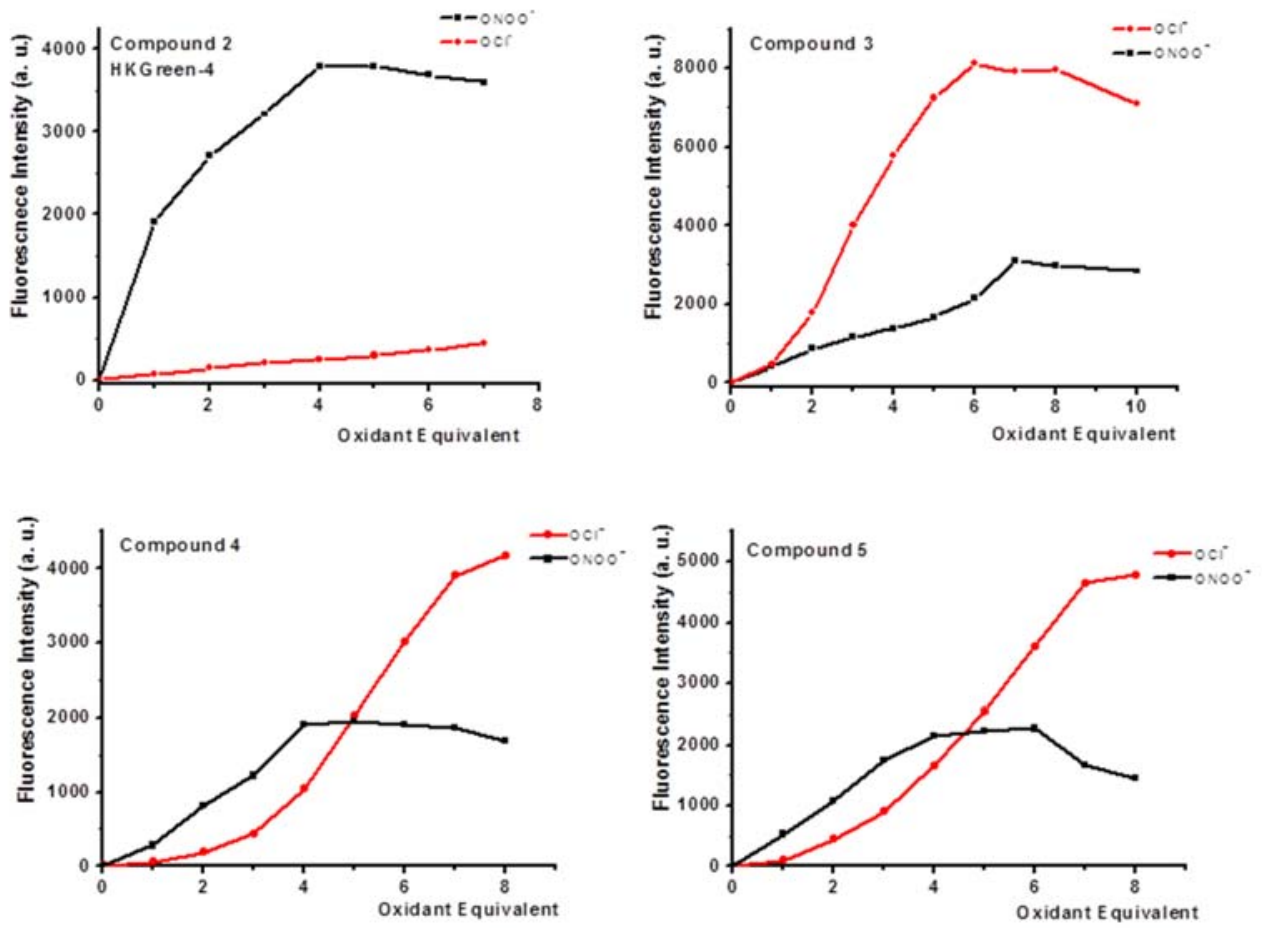

Figure S2. Fluorescence intensities of compounds 2-5 after treated with various amounts of hypochlorous acid and peroxynitrite. The compounds were in $0.1 \mathrm{M}$ phosphate buffer ( $\mathrm{pH}$ 7.4) at the concentration of $1 \mu \mathrm{M}$. The fluorescence intensities were recorded at $535 \mathrm{~nm}$ with excitation at 517 nm. 
Scheme S6. Proposed mechanisms of reactions between HKGreen-4/compound 3 and $\mathrm{ONOO}^{-} / \mathrm{HOCl}$<smiles></smiles>

HKGreen-4 or compound 3

$\mathrm{X}=\mathrm{O}$ or $\mathrm{NH}$

$\mathrm{Rh}=$ rhodol core structure

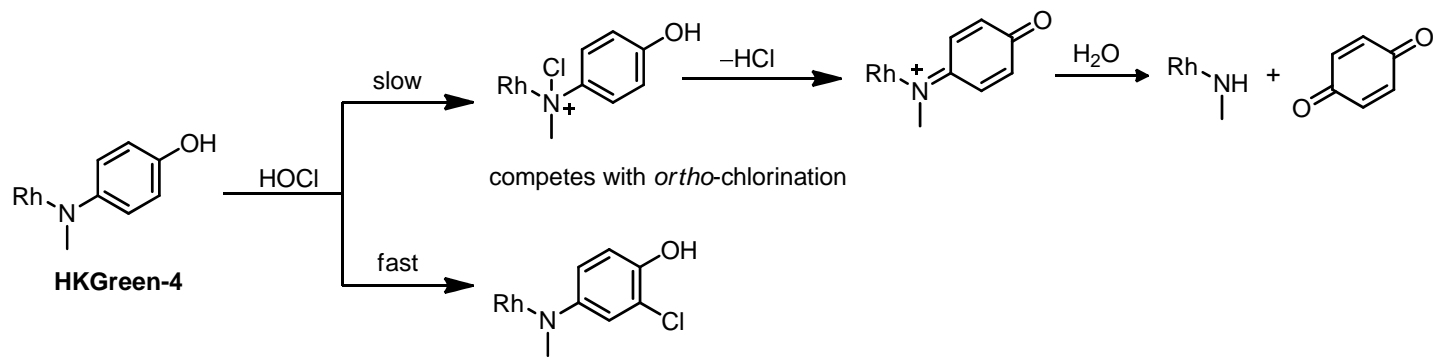

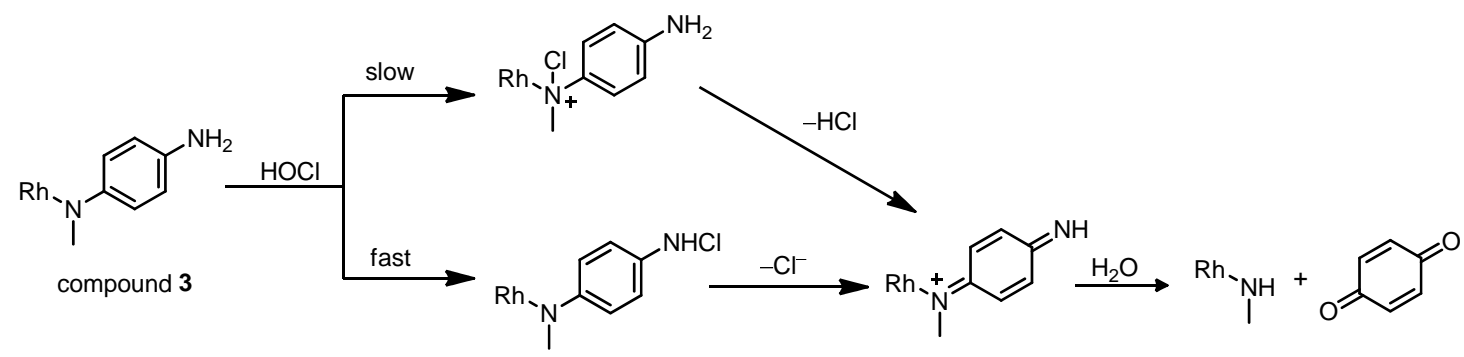

HKGreen-4 and compound 3 are probably oxidized by peroxynitrite through two-electron oxidation to form the iminium ions, followed by water hydrolysis to afford the fluorescent product. Unlike peroxynitrite, hypochlorous acid reacts with HKGreen-4 through $N$-chlorination of the diarylamine moiety and more preferably through chlorination at phenol ortho positions, inefficiently yielding the fluorescent product. By contrast, $N$-chlorination of the readily accessible amino group of compound $\mathbf{3}$ with hypochlorous acid enables the generation of the fluorescent product easily. 


\section{Photophysical Characterization of HKGreen-4 for Peroxynitrite Detection}

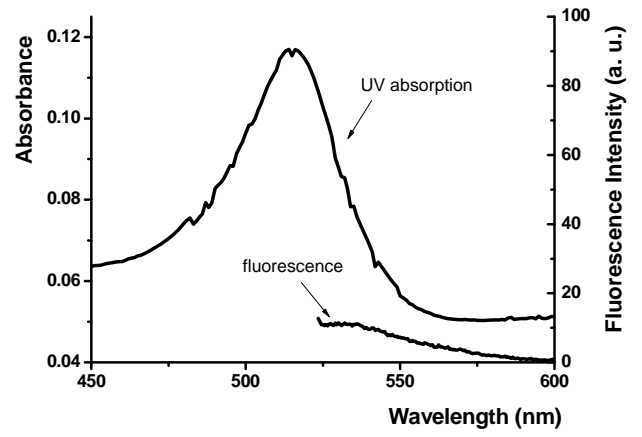

Figure S3. UV and fluorescence spectra of HKGreen-4 $(1 \mu \mathrm{M})$ in $0.1 \mathrm{M}$ phosphate buffer at $\mathrm{pH}$ 7.4. The fluorescence spectrum of HKGreen-4 was recorded with excitation at $517 \mathrm{~nm}$.

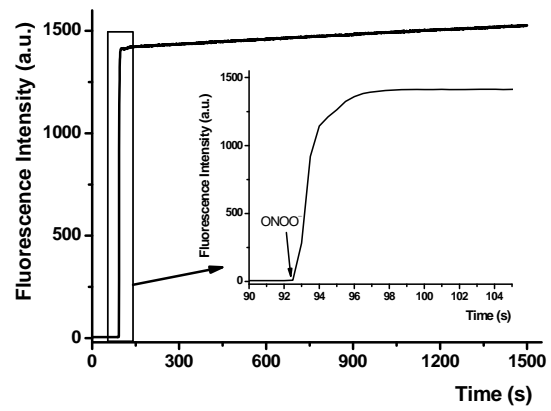

Figure S4. Time course in the detection of peroxynitrite with HKGreen-4 monitored by fluorescence. The probe was dissolved in $0.1 \mathrm{M}$ phosphate buffer $(\mathrm{pH}$ 7.4) at a $1 \mu \mathrm{M}$ concentration. The fluorescence intensity was monitored with time at emission of $535 \mathrm{~nm}$ (excitation at $517 \mathrm{~nm}$ ). Peroxynitrite was added into the probe solution at the time point indicated by the arrow. 


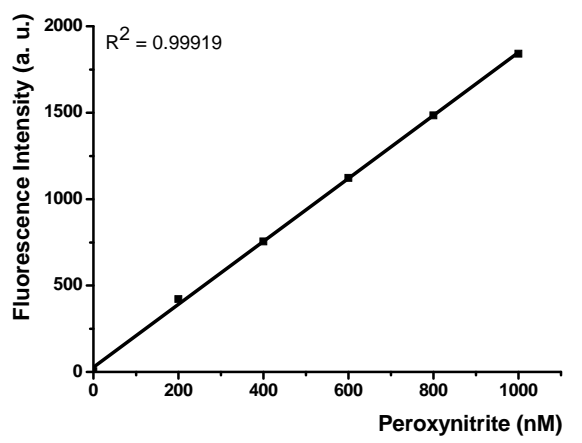

Figure S5. Linear correlation between the fluorescence emission intensity of HKGreen-4 $(1 \mu \mathrm{M}$ in 0.1 M phosphate buffer at $\mathrm{pH}$ 7.4) and the concentration of peroxynitrite. The fluorescence intensity was determined at $535 \mathrm{~nm}$ with excitation at $517 \mathrm{~nm}$.

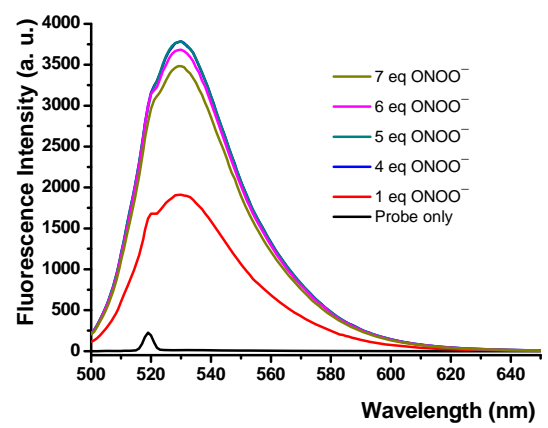

Figure S6. Fluorescence spectra of $1 \mu \mathrm{M}$ HKGreen-4 (0.1 M phosphate buffer at pH 7.4) in the presence of different amounts of $\mathrm{ONOO}^{-}$. Spectra were acquired at $25{ }^{\circ} \mathrm{C}$ with excitation at $517 \mathrm{~nm}$.

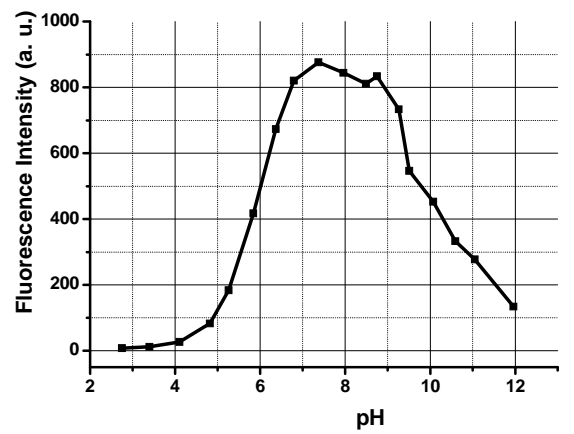

Figure S7. pH-dependent profile of HKGreen-4 in the detection of peroxynitrite. The probe was dissolved in $\mathrm{pH} 7.4$ phosphate buffer $(0.1 \mathrm{M})$ at $1 \mu \mathrm{M}$ concentration. $6 \mathrm{M} \mathrm{KOH}$ solution or 
concentrated phosphoric acid was used to adjust the $\mathrm{pH}$. The final concentration of added peroxynitrite was $0.5 \mu \mathrm{M}$. The fluorescence intensity was recorded at $535 \mathrm{~nm}$ with the excitation at 517 $\mathrm{nm}$. The $\mathrm{pH}$ differences before and after peroxynitrite addition were determined to be less than 0.05 . The left part of this bell-shaped curve is ascribed to the $\mathrm{pH}$-dependent fluorescence of the released $\mathrm{N}$ methylrhodol 19 and/or acid-base equilibrium of peroxynitrite, while the right part of the bell-shaped curve is probably ascribed to the deprotonation of probe phenolic $\mathrm{OH}$.

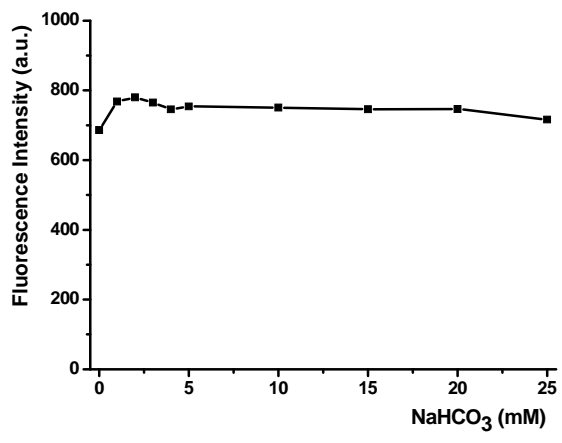

Figure S8. Effects of $\mathrm{NaHCO}_{3}$ in the detection of peroxynitrite with HKGreen-4. The probe was dissolved in $\mathrm{pH} 7.4$ phosphate buffer $(0.1 \mathrm{M})$ at $1 \mu \mathrm{M}$ concentration. Different amounts of $\mathrm{NaHCO}_{3}$ were added into the probe solution to the indicated concentrations. The final concentration of added peroxynitrite was $0.5 \mu \mathrm{M}$.
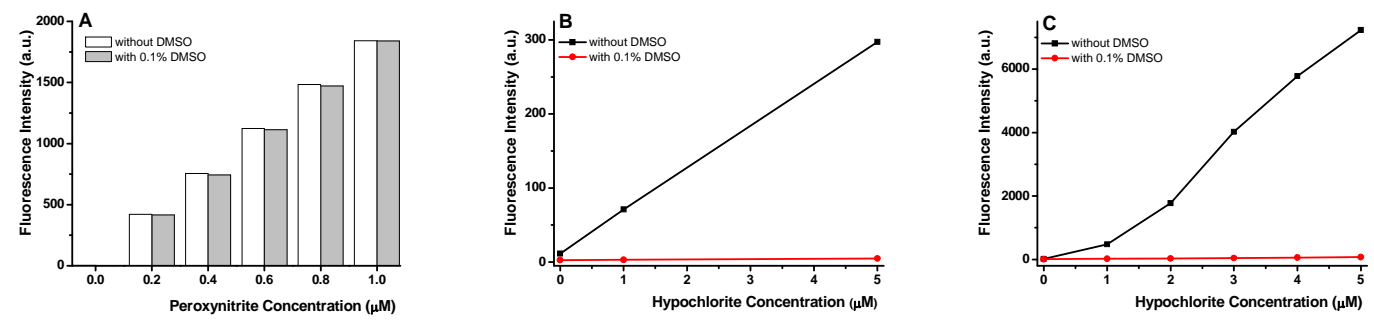

Figure S9. Effects of DMSO in the detection of peroxynitrite and hypochlorous acid with HKGreen4 and compound 3. (A) Peroxynitrite detection with HKGreen-4 (1 $\mu \mathrm{M}$ in $0.1 \mathrm{M}$ phosphate buffer at $\mathrm{pH}$ 7.4) in the absence or presence of DMSO. (B) Responses of HKGreen-4 toward hypochlorous acid $(1 \mu \mathrm{M}$ in $0.1 \mathrm{M}$ phosphate buffer at $\mathrm{pH}$ 7.4) in the absence or presence of DMSO. (C) Hypochlorous acid detection with compound $3(1 \mu \mathrm{M}$ in $0.1 \mathrm{M}$ phosphate buffer at $\mathrm{pH} 7.4)$ in the absence or presence of DMSO. 


\section{Reaction of HKGreen-4 with Peroxynitrite}<smiles>CN(c1ccc(O)cc1)c1ccc2c(-c3ccccc3C(=O)O)c3ccc(=O)cc-3oc2c1</smiles>

HKGreen-4

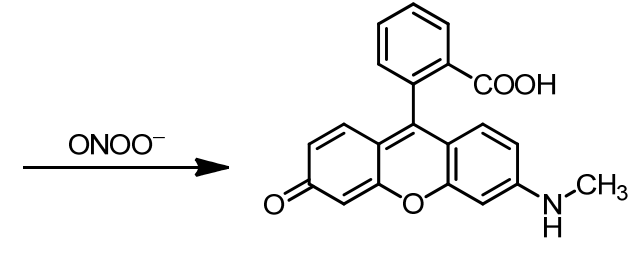

19, N-methylrhodol

To a solution of probe HKGreen-4 (16 mg, $0.037 \mathrm{mmol}$ ) in a mixed solvent of DMF (3.5 $\mathrm{mL}$ ) and $0.1 \mathrm{M}$ phosphate buffer at $\mathrm{pH} 7.4(350 \mathrm{~mL})$ was added an alkaline solution of peroxynitrite (2.0 equiv) dropwise at $\mathrm{rt}$. After stirred for half an hour, the reaction mixture was extracted with $\mathrm{DCM} / i-\mathrm{PrOH}$ three times. The combined organic layers were dried over anhydrous $\mathrm{Na}_{2} \mathrm{SO}_{4}$, and concentrated. The resulting residue was purified by silica gel column chromatography to give the fluorescent product 19 ( $4 \mathrm{mg}, \sim 30 \%$ yield). The residue was also analyzed by HPLC and LC-MS (Figure S10). Analytical HPLC was performed with an Agilent 1100 HPLC system. The UV detector was set at $254 \mathrm{~nm}$ and $500 \mathrm{~nm}$. The samples were prepared as $\mathrm{MeOH}$ stock solutions, and were eluted from an Alltima reverse-phase C18 column $(4.6 \times 250 \mathrm{~mm}, 5 \mu \mathrm{m})$ with a linear gradient of water (containing $0.1 \% \mathrm{TFA})$ and methanol $(60-90 \%$ methanol in $10 \mathrm{~min})$ at a flow rate of $1 \mathrm{~mL} / \mathrm{min}$. Samples were detected by absorbance at $500 \mathrm{~nm}$, and were also identified with an Agilent 6120 Quadrupole LC/MS System coupled to the HPLC system using ESI and APCI ionization sources.

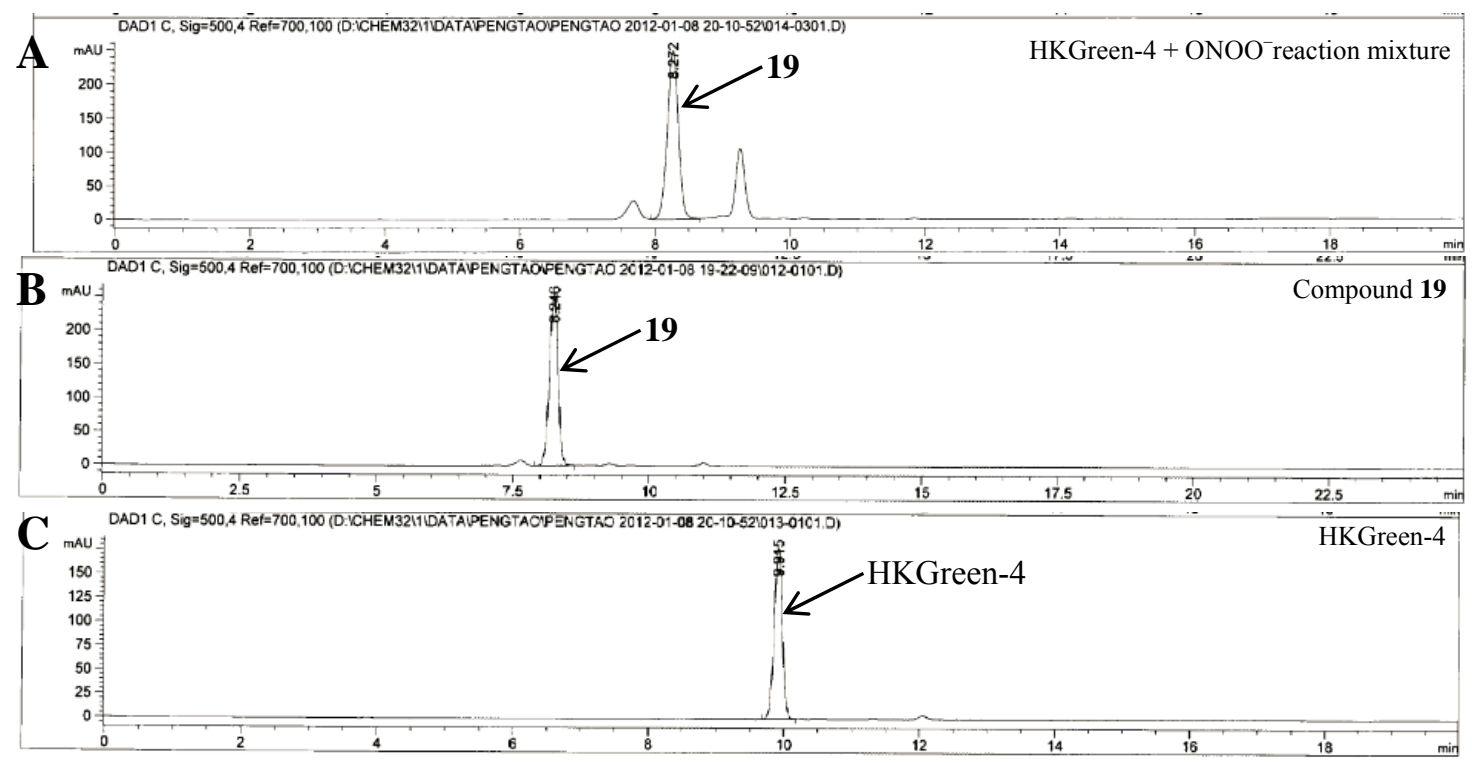




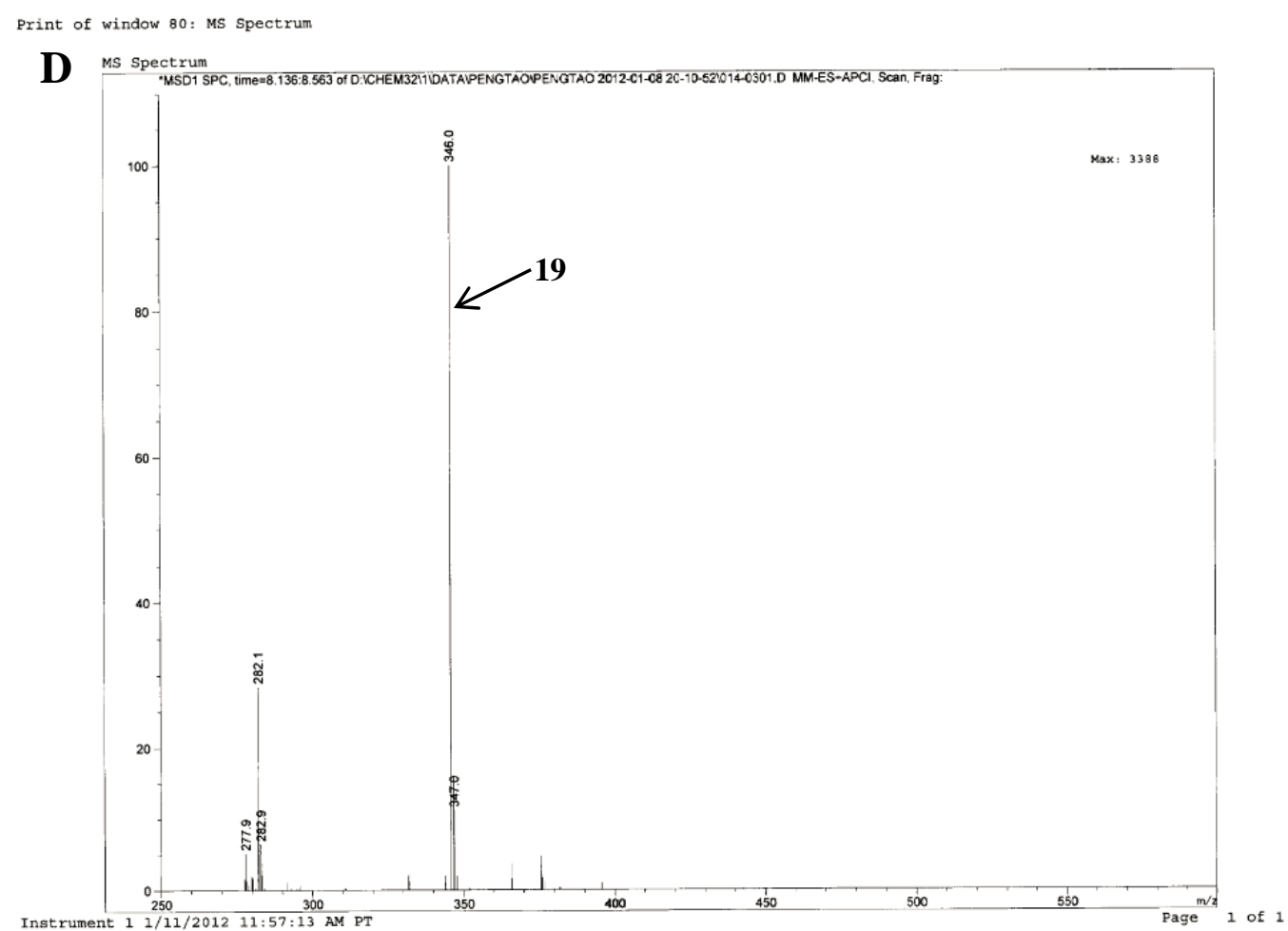

Print of window 80: MS Spectrum

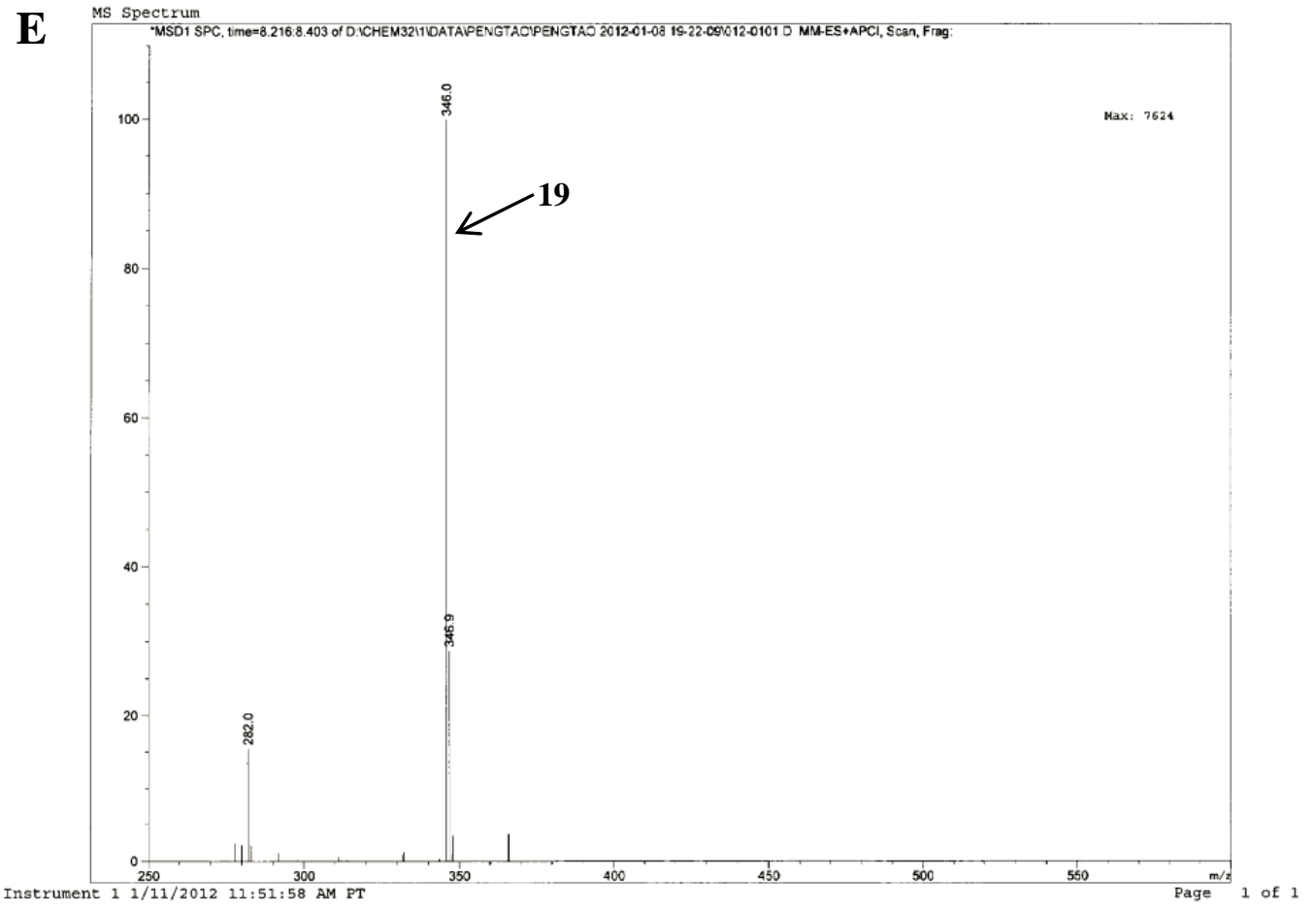




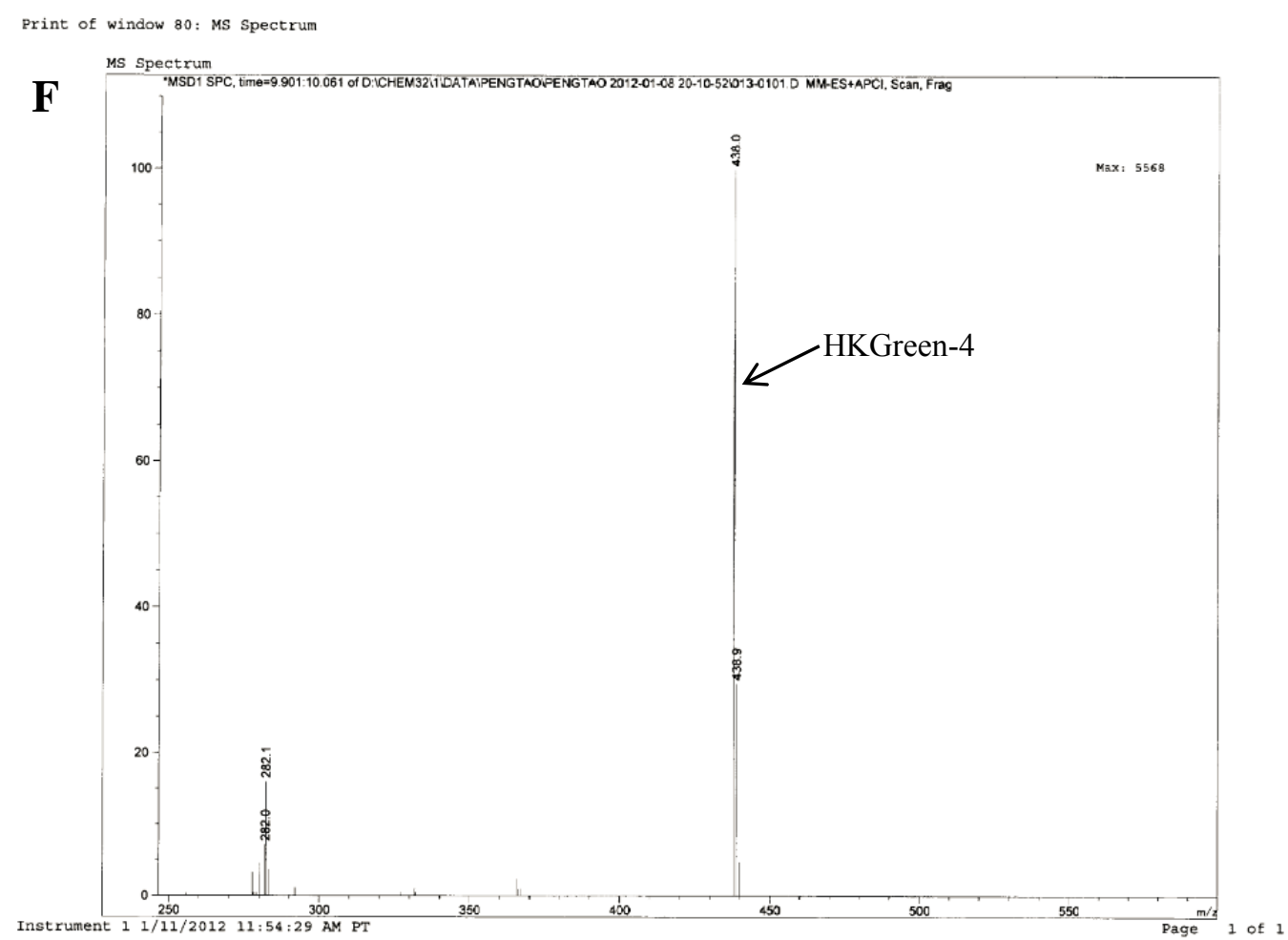

Figure S10. Detection of $N$-methylrhodol 19 as the fluorescent product in the reaction of HKGreen4 with peroxynitrite using HPLC and LC-MS. UV absorption was monitored at the wavelength of 500 $\mathrm{nm}$ with the reference set at $360 \mathrm{~nm}$. (A) HPLC analysis of reaction product between HKGreen-4 and peroxynitrite indicates the formation of $\mathbf{1 9}$ at the retention time of $8.2 \mathrm{~min}$. (B) HPLC analysis of authentic sample of 19 indicates its retention time of $8.2 \mathrm{~min}$. (C) HPLC analysis of HKGreen-4 indicates its retention time of $9.9 \mathrm{~min}$. (D) MS spectrum at the retention time of $8.2 \mathrm{~min}$ shown in (A) identifies the production of $\mathbf{1 9}$ in the reaction of HKGreen-4 with peroxynitrite. (E) MS spectrum of the authentic sample of $\mathbf{1 9}$ at the retention time of 8.2 min shown in (B). (F) MS spectrum of HKGreen-4 at the retention time of 9.9 min shown in (C).

\section{Biological Assays of HKGreen-4}

\section{Cell culture}

RAW264.7 mouse macrophages were acquired from ATCC and maintained in DMEM supplemented with 10\% heat-inactivated fetal bovine serum (Gibco) and 1\% penicillin/streptomycin, at $37^{\circ} \mathrm{C}$ in $5 \% \mathrm{CO}_{2}$. The growth medium was changed every two to three days. Cells were grown to $80 \%$ confluence prior to experiment. For confocal imaging, cells were typically seeded at a density of $2 \times 10^{4}$ cells $/ \mathrm{mL}$ in 35-mm confocal dish (Mat-Tek: MA, USA). BV-2 mouse microglia were acquired 
as a gift from Department of Pediatrics, The University of Hong Kong, and maintained in DMEM supplemented with 10\% heat-inactivated fetal bovine serum (Gibco) and 1\% penicillin/streptomycin, at $37^{\circ} \mathrm{C}$ in $5 \% \mathrm{CO}_{2}$. For confocal imaging, cells were typically seeded at a density of $1 \times 10^{4}$ cells $/ \mathrm{mL}$ in 35-mm confocal dish (Mat-Tek: MA, USA). C17.2 mouse neural progenitor cells were acquired as a gift from School of Chinese Medicine, The University of Hong Kong, and maintained in DMEM (highglucose; $4 \mathrm{mM} \mathrm{L-glutamine;} \mathrm{sodium} \mathrm{pyruvate)} \mathrm{supplemented} \mathrm{with} 10 \%$ heat-inactivated fetal bovine serum (Gibco) and 1\% penicillin/streptomycin, at $37^{\circ} \mathrm{C}$ in $5 \% \mathrm{CO}_{2}$. $\mathrm{CHO}$ (Chinese hamster ovarian) cells were acquired as a gift from Department of Chemistry, The University of Hong Kong, and maintained in MEM (with GlutaMAX; Gibco) supplemented with 10\% heat-inactivated fetal bovine serum (Gibco) and $1 \%$ penicillin/streptomycin, at $37{ }^{\circ} \mathrm{C}$ in $5 \% \mathrm{CO}_{2}$. To generate primary mouse bone marrow-derived macrophages, bone marrow cells were collected from femur and tibia, and treated with RBC lysis buffer to deplete red blood cells. Resultant bone marrow progenitor cells were then differentiated into macrophages with $20 \mathrm{ng} / \mathrm{mL}$ M-CSF (macrophage colony-stimulating factor) for 5 days.

MTT assay

MT'T assay was utilized to investigate the cytotoxicity of HKGreen-4A. 3-(4,5Dimethylthiazol-2-yl)-2,5-diphenyl tetrazolium bromide (MTT) is a yellow tetrazolium salt and can be reduced to formazan crystals, which are insoluble in aqueous solutions, by active mitochondria in living cells. The resulting intracellular purple formazan can be dissolved in acidified sodium dodecyl sulfate (SDS), and therefore quantified by measuring absorption of the solution. To build a standard curve or a growth curve, the cells were seeded in a 96-well plate and incubated with $200 \mu \mathrm{L}$ of culture media for $2 \mathrm{~h}$. Then different amounts of probes were added to the wells for further incubation of indicated times. For the standard curve, no probe was added. The culture media was then removed. Portions of $100 \mu \mathrm{L}$ MTT solution ( $0.5 \mathrm{mg}$ in $1 \mathrm{~mL}$ of Hanks' balanced salt solution) were added to the wells and the cells were further incubated at $37^{\circ} \mathrm{C}$ for $2 \mathrm{~h}$. Solubilization solutions $(100 \mu \mathrm{L})$ were then added and incubated with the cells overnight. The absorption of each well was measured at a wavelength of 570 $\mathrm{nm}$ with a multiwell scanning spectrophotometer (ELISA reader). The cells viability was calculated according to the following equation:

Cell viability $(\%)=100 \times \mathrm{A}_{\text {with probe }} / \mathrm{A}_{\text {control. }}$. 


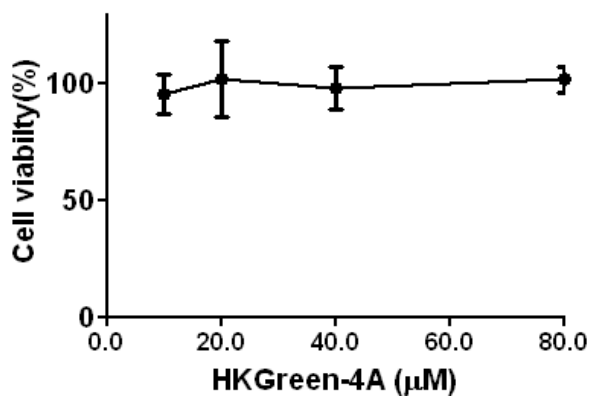

Figure S11. Cytotoxicity of HKGreen-4A in cultured RAW 264.7 macrophage cells. Cells were incubated with the probes at corresponding concentrations for $24 \mathrm{~h}$. Cell viability was measured by MTT assay and the results are reported as percentage relative to untreated cells (mean \pm SD).

\section{Bacterial culture and moi determination}

To generate a standard curve for estimating moi (multiplicity of infection), serial plating of bacterial culture diluents of known O.D.600nm was performed. Briefly, antibiotic-free LB (Luria broth) medium (4 mL) was inoculated with E. coli (strain JM109) recovered from liquid nitrogen stock $(30 \%$ sterile glycerol), for overnight incubation at $37^{\circ} \mathrm{C}$ with rigorous shaking at $220 \mathrm{rpm}$ (Centrifuge 5804; Eppendorf: Hamburg, Germany). Bacteria were allowed to grow to log phase (O.D.600nm $\sim 0.6-0.8$ ) and were harvested by centrifugation at 1,000 rpm (Centrifuge 5804; Eppendorf: Hamburg, Germany) for $10 \mathrm{~min}$. Cell pellet was resuspended in $1 \mathrm{~mL}$ sterile HBSS (Hank's balanced salt solution) and diluted to a suitable range of O.D. (optic density) at $600 \mathrm{~nm}: 0.1$ to 1 . After O.D.600nm determination, resuspended bacteria were further serially diluted (successively by a dilution factor of 10 ) in $2-\mathrm{mL}$ Eppendorf tubes, for the following range of dilution factors: $10 \times, 10^{2} \times, 10^{3} \times, 10^{4} \times, 10^{5} \times, 10^{6} \times$. For bacteria of different O.D. $600 \mathrm{~nm}$, a $100-\mu \mathrm{L}$ inoculum (at $10^{5 \times}$ and $10^{6} \times$ ) was aseptically plated unto antibiotic-free LB agar plates in triplicates, and incubated for 2 days at $37^{\circ} \mathrm{C}$. Resultant colonies on the triplicate plates were counted to obtain a mean count corresponding to CFU counts (number of colony-forming units). CFU counts were plotted as a dependent variable against corresponding O.D.600nm as an independent variable to obtain a standard curve. Prior to bacterial infection experiment, overnight liquid culture of E. coli was grown to $\log$ phase in LB at $37^{\circ} \mathrm{C}$. After harvest by centrifugation, cell pellet was washed $1 \times$ with HBSS, resuspended and diluted with HBSS to concentrations suitable for O.D. measurement (usually about O.D.600nm $=0.8-2$ ). Based on the measured O.D.600nm, an estimated CFU count was obtained from the pre-determined standard curve above. Bacteria were then further diluted with HBSS to a desired moi for infection of macrophages. 
Preparation of heat killed bacteria

Heat-killed E. coli only was used for confocal fluorescence imaging, in compliance with local ethics regulations for microscopy in biomedical research. E. coli was grown to log phase and harvested by centrifugation. After determination of O.D.600nm and dilution with HBSS to suitable moi, E. coli suspension in 2-mL Eppendorf tubes was incubated in a Stuart block heater (Bibby Scientific: Staffordshire, UK) at $90^{\circ} \mathrm{C}$ for $40 \mathrm{~min}$. Immediately before treatment, bacteria were thoroughly resuspended by rigorous vortex and pipetting.

\section{Confocal fluorescence imaging in live cells}

For induction of endogenous $\mathrm{O}_{2}{ }^{--}$and ONOO- formation, RAW264.7 cells were seeded into 35-mm glass-bottom culture dishes (Mat-Tek: Ashland MA, USA) in DMEM medium (normal glucose) supplemented with 10\% FBS (fetal bovine serum), 1\% P/S (penicillin/streptomycin; GibcoInvitrogen) in a seeding volume of $2 \mathrm{~mL}$ per well, at a density of $2 \times 10^{4}$ cells $/ \mathrm{mL}$. After attachment and overnight culture at $37^{\circ} \mathrm{C}$, old culture medium was discarded, followed by washing with sterile HBSS to remove residual FBS and medium dye. Heat-killed E. coli $(\mathrm{moi}=100)$ suspension was diluted with treatment medium (DMEM without phenol red, supplemented with 3\% FBS, $0.6 \mathrm{mM} \mathrm{L}$-arginine, $0.01 \%$ chloramphenicol) and subsequently added to RAW264.7 cells in a treatment volume of $1.5 \mathrm{~mL}$ per dish. Prior to desired time points of imaging (usually, $30 \mathrm{~min}$ before $\mathrm{t}=14 \mathrm{~h}$ post-infection), bacteria-infected or drug-treated RAW264.7 cells were loaded with appropriate fluorescent dyes and further incubated at $37^{\circ} \mathrm{C}$ for $30 \mathrm{~min}$ before image acquisition. Briefly, MitoSOX Red $(2.5 \mu \mathrm{M})$, HKGreen-4A $(10 \mu \mathrm{M})$ and the nuclear DNA dye Hoechst $33342(75 \mathrm{ng} / \mathrm{mL}$; Invitrogen Molecular Probes) were added to $1 \mathrm{~mL}$ recovered treatment medium, mixed and immediately returned to the culture dish. At the end of 30-min probe incubation, the culture dish was mounted onto a live cell support module (AxioVision; Zeiss: Jena, Germany) maintained at $37^{\circ} \mathrm{C}$ and $5 \% \mathrm{CO}_{2}$. Imaging was performed with LSM Meta 510 (Zeiss: Jena, Germany). Z-stack imaging was conducted with an oil lens by acquiring 5 consecutive photosections ( $0.37 \mu \mathrm{m}$ per section) at $63 \times 4$ magnification about the equatorial region of host cells (where diameters of the nuclei are generally largest) with the following imaging parameters: MitoSOX Red $\left(\lambda_{\mathrm{ex}}=543 \mathrm{~nm} ; \lambda_{\mathrm{em}}=565-615 \mathrm{~nm}\right.$ band-pass; laser intensity $=26 \%$ ), HKGreen-4A $\left(\lambda_{\text {ex }}=488 \mathrm{~nm} ; \lambda_{\text {em }}=500-550 \mathrm{~nm}\right.$ band-pass; laser intensity $\left.=26 \%\right)$, and Hoechst 33342 (two-photon mode; $\lambda_{\mathrm{ex}}=790 \mathrm{~nm} ; \lambda_{\mathrm{em}}=435-485 \mathrm{~nm}$ band-pass; laser intensity $=3 \%$ ). Photosections from respective channels were collapsed into a single merged image and exported in appropriate image format (TIF or JPG). For imaging of cell morphology and probe distribution, the mitochondrial organelle dye MitoTracker Red (100 nM; Invitrogen Molecular Probes) was used in place of MitoSOX 
Red.

Confocal fluorescence imaging in live tissues

For detection of $\mathrm{ONOO}^{-}$under atherosclerotic conditions, apolipoprotein E knockout $\left(\mathrm{ApoE}^{-/-}\right)$mice were chosen as an atherosclerosis model to compare with wild-type C57BL/6 mice, which served as a reference for basal $\mathrm{ONOO}^{-}$formation in healthy animals. Each group ( $\mathrm{n}=6$ males) was fed on normal chow diet for 20 weeks. Atherosclerotic plaques and other symptoms had been confirmed in the ApoE ${ }^{-/-}$mice by conventional histological methods (oil red $\mathrm{O}$ staining) and microscopic inspection. Mice were fasted overnight before tissue sampling. 10\% pentobarbital $(0.1$ $\mathrm{mL} / \mathrm{g}$ ) was injected as an anesthetic during sacrifice. Mouse abdomen and chest were surgically opened to reveal the heart. A small aperture was made by cutting at the right atrium. Initial perfusion (5 min) was performed with HBSS (Hank's balanced salt solution; Gibco) to remove blood. HKGreen-4A (2 $\mu \mathrm{M}$ ) was next added to the perfusion buffer (total $10 \mathrm{~mL}$ HBSS, supplemented with $0.6 \mathrm{mM}$ L-arginine for sustaining ${ }^{\circ} \mathrm{NO}$ production) for tissue staining during perfusion $(10 \mathrm{~min})$. The heart was then excised and bathed in the perfusion buffer with HKGreen-4A $(2 \mu \mathrm{M})$ and $0.6 \mathrm{mM}$ L-arginine, for another 20 min to allow sufficient incubation. To avoid nonselective ROS induction and heterogeneous tissue decay, staining was terminated by fixing with 4\% PFA (paraformaldehyde) in cold PBS, followed by quenching with $100 \mathrm{mM}$ glycine and wash with PBS for desalting. The heart tissues were embedded in OCT (optimal cutting temperature) compound and stored at $-20^{\circ} \mathrm{C}$. The tissues were then cryosectioned at an interval of $10 \mu \mathrm{m}$. Regions of interest, the smooth muscles of mouse aortic root, were selected and mounted onto a glass slide (Thermo Scientific). Image acquisition was performed with LSM Meta 510 (Zeiss: Jena, Germany). Z-stack imaging was conducted with an oil lens by acquiring 5 or 20 consecutive photosections $(0.37 \mu \mathrm{m}$ per section) at $63 \times 1$ magnification with the following imaging parameters for HKGreen-4A: two-photon mode; $\lambda_{\mathrm{ex}}=730 \mathrm{~nm} ; \lambda_{\mathrm{em}}=500-550 \mathrm{~nm}$ band-pass; laser intensity $=4 \%$. Photosections from were collapsed into a single merged image and exported in appropriate image format (TIF or JPG) before image processing and analysis. 


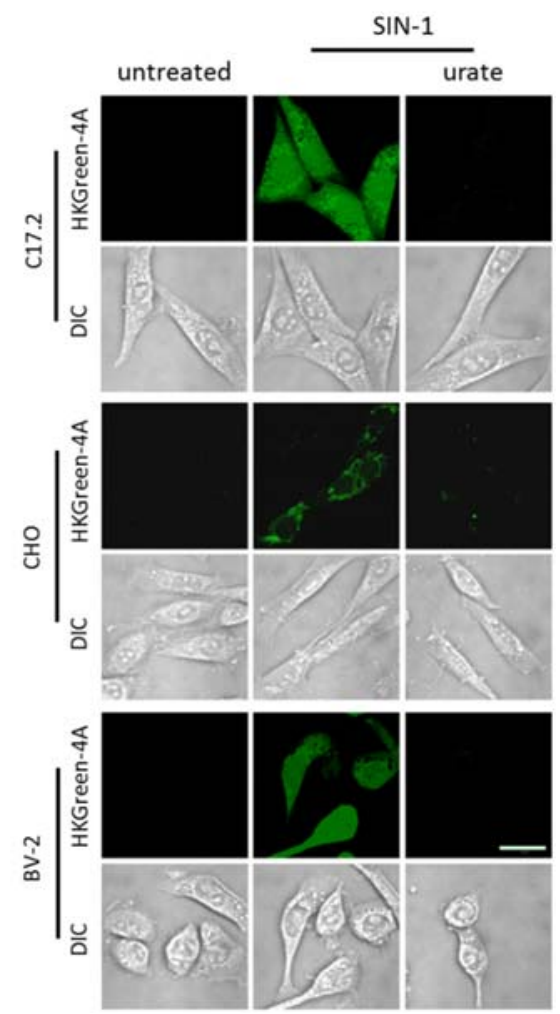

Figure S12. Imaging of exogenous $\mathrm{ONOO}^{-}$with HKGreen-4A in different types of live cells. C17.2 mouse neural progenitor cells, $\mathrm{CHO}$ (Chinese hamster ovarian) cells, or BV-2 mouse microglia were co-incubated with HKGreen-4A (10 $\mu \mathrm{M})$ and SIN-1 $(50 \mu \mathrm{M})$ as $\mathrm{ONOO}^{-}$donor for $1 \mathrm{~h}$, followed by confocal imaging. Sodium urate $(100 \mu \mathrm{M})$ was used as an $\mathrm{ONOO}^{-}$scavenger. "DIC" represents bright field image. Scale bar represents $20 \mu \mathrm{m}$. 


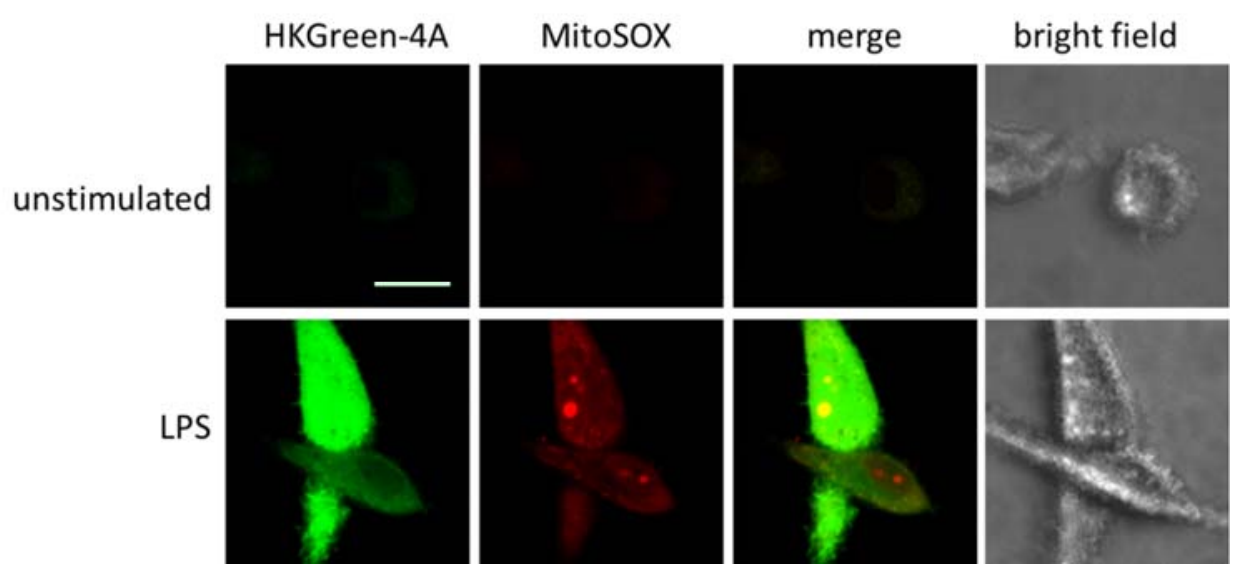

Figure S13. Imaging of endogenous $\mathrm{ONOO}^{-}$with $\mathbf{H K G r e e n - 4 A}$ in primary macrophages. Mouse bone marrow progenitor cells were differentiated with M-CSF $(20 \mathrm{ng} / \mathrm{mL} ; 5$ days) into macrophages, which were then stimulated with LPS (E. coli K12;1 $\mu \mathrm{g} / \mathrm{mL}$ ) for $18 \mathrm{~h}$. Cells were co-incubated with HKGreen-4A $(10 \mu \mathrm{M})$ and MitoSOX Red $\left(\mathrm{O}_{2}{ }^{--}\right.$probe; $\left.2.5 \mu \mathrm{M}\right)$ for $30 \mathrm{~min}$, before confocal imaging. Scale bar represents $10 \mu \mathrm{m}$.

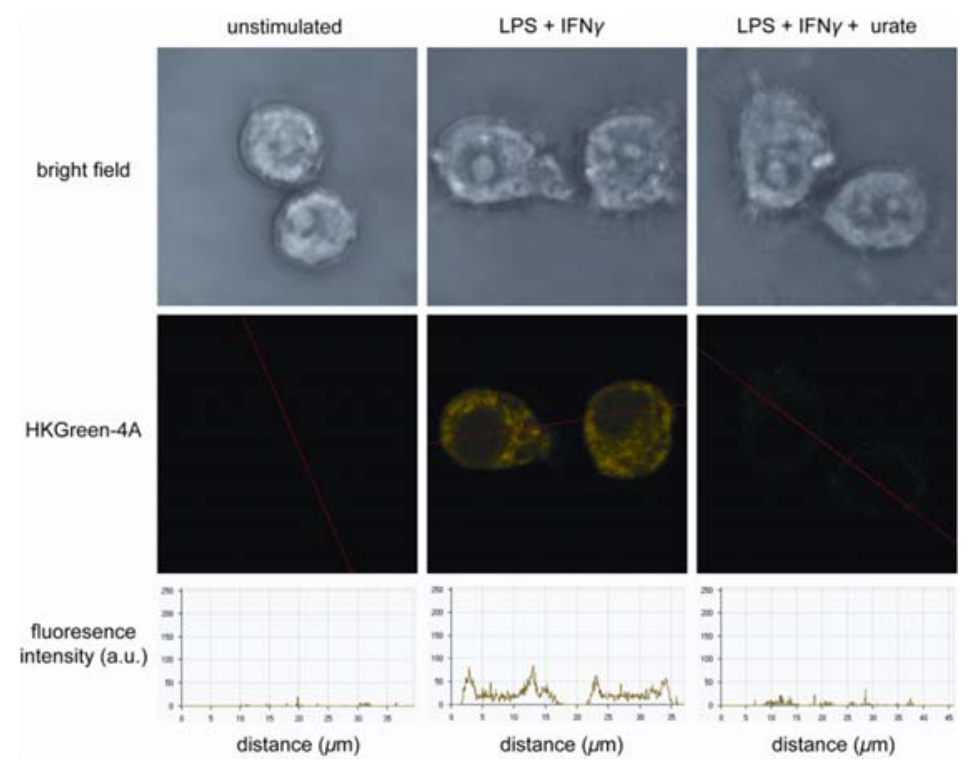

Figure S14. Two-photon confocal imaging of endogenous $\mathrm{ONOO}^{-}$with HKGreen-4A in RAW264.7 mouse macrophages. Cells were stimulated with LPS (Salmonella t.; $1 \mu \mathrm{g} / \mathrm{mL}$ ) plus IFN- $\gamma$ (mouse; 100 $\mathrm{ng} / \mathrm{mL})$ for $14 \mathrm{~h}$. Cells were incubated with HKGreen-4A $(10 \mu \mathrm{M})$ for $30 \mathrm{~min}$, before confocal imaging (two-photon mode; $\lambda_{\mathrm{ex}}=730 \mathrm{~nm}, \lambda_{\mathrm{em}}=500-550 \mathrm{~nm}$ band-pass; laser intensity $=4 \%$ ). Sodium urate $(100 \mu \mathrm{M})$ was used to scavenge $\mathrm{ONOO}^{-}$. Profiles of fluorescence intensity across selected region of 
interest were generated with LSM Meta 510 image analysis software.

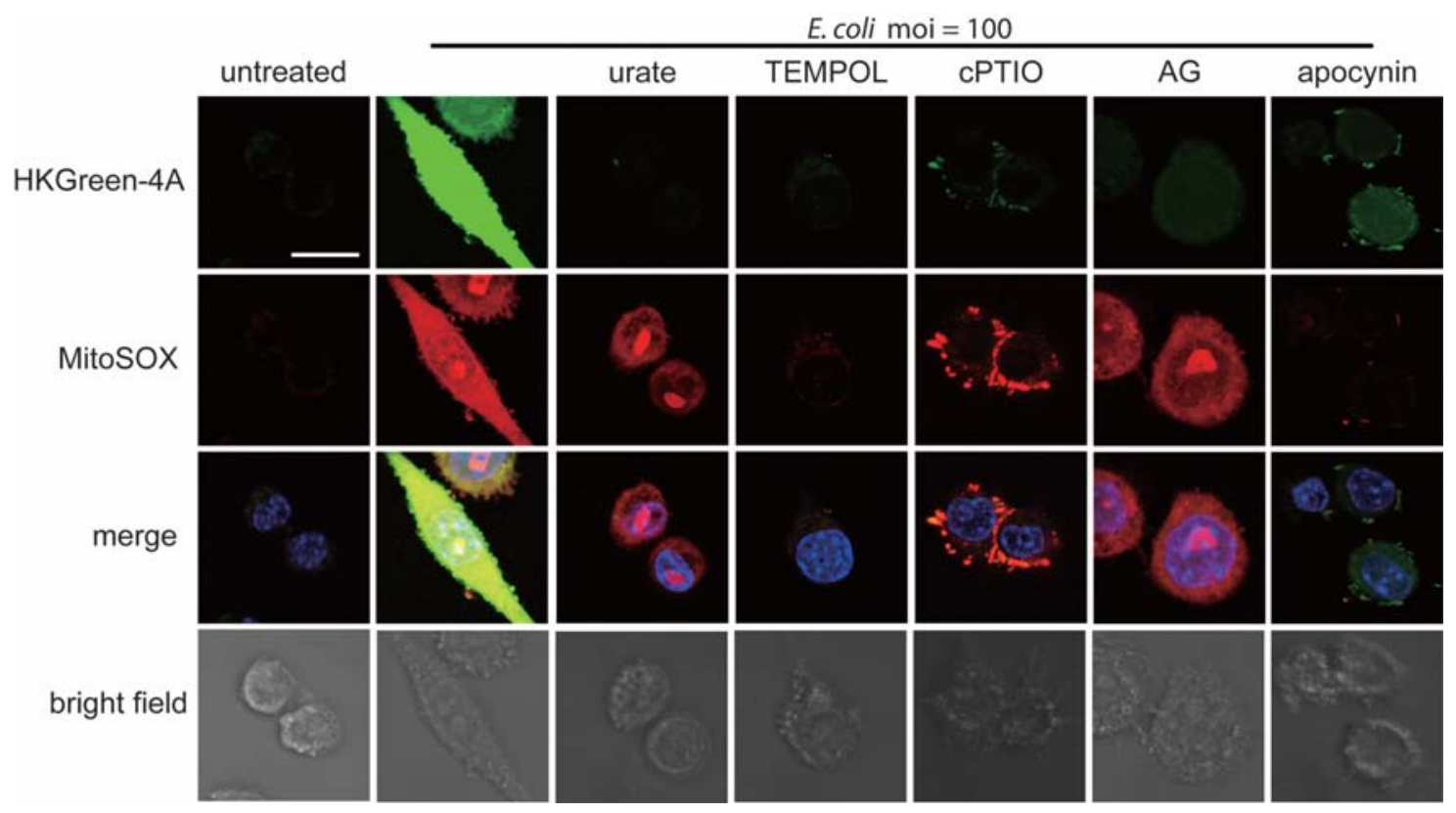

Figure S15. Validation of enzymatic pathways involved in endogenous $\mathrm{ONOO}^{-}$formation in E. colichallenged RAW264.7 macrophages. Cells were treated with heat-killed E. coli (moi $=100)$ for 14 h, and then stained with HKGreen-4A $(10 \mu \mathrm{M})$, MitoSOX $(2.5 \mu \mathrm{M})$, and Hoechst $33342(75 \mathrm{ng} / \mathrm{mL})$ in the presence or absence of urate $\left(\mathrm{ONOO}^{-}\right.$scavenger; $\left.100 \mu \mathrm{M}\right)$, TEMPOL $\left(\mathrm{O}_{2}{ }^{-}{ }^{-}\right.$scavenger; $\left.300 \mu \mathrm{M}\right)$, or cPTIO ( ${ }^{N O}$ scavenger; $125 \mu \mathrm{M}$ ) for $30 \mathrm{~min}$, before confocal imaging. Aminoguanidine (AG; 300 $\mu \mathrm{M})$ and apocynin $(500 \mu \mathrm{M})$, which inhibit NOS and NOX, respectively, were added to cells during stimulation. "Merge" represents overlays of all fluorescence channels including Hoechst. Scale bar represents $10 \mu \mathrm{m}$. 


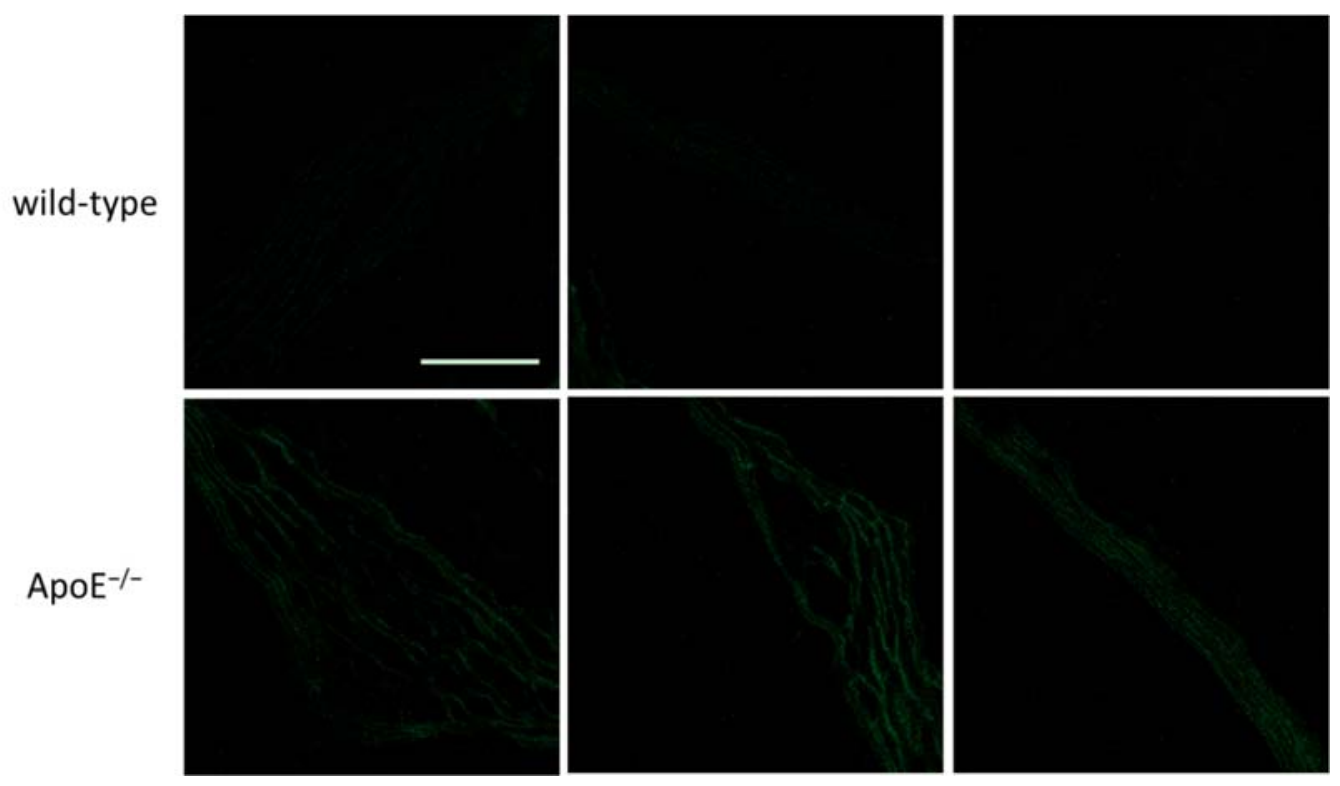

Figure S16. Representative imaging of endogenous $\mathrm{ONOO}^{-}$in single photosections of smooth muscles in mouse aortic root in a mouse model of atherosclerosis. Living smooth muscles of the mouse aortic root were stained with HKGreen-4A ( $2 \mu \mathrm{M})$ for 30 min by perfusion, fixed, cryosectioned and mounted for two-photon confocal imaging. Six animals were used in each group. Scale bar represents $50 \mu \mathrm{m}$.
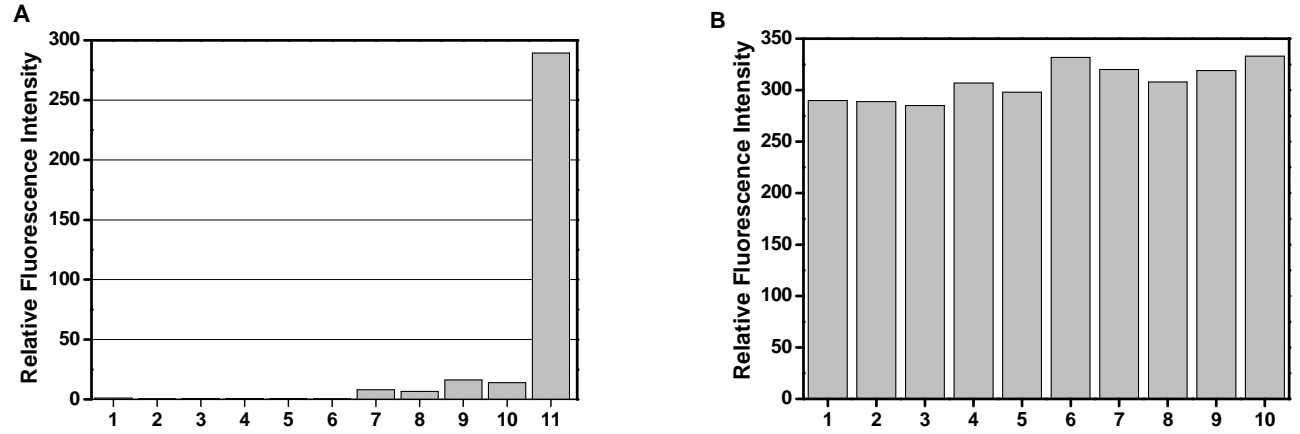

Figure S17. (A) Fluorescence increases of HKGreen-4 $(1 \mu \mathrm{M})$ towards various ROS and RNS. (1) probe only; (2) 10 equiv ${ }^{1} \mathrm{O}_{2}$; (3) 10 equiv ${ }^{\circ} \mathrm{NO}$; (4) 10 equiv ROO’; (5) 10 equiv $\mathrm{O}_{2}{ }^{\bullet-}$; (6) 10 equiv $\mathrm{H}_{2} \mathrm{O}_{2}$; (7) 10 equiv $\mathrm{NO}_{2}$; (8) 10 equiv $\mathrm{CO}_{3}{ }^{--}$; (9) 1 equiv ${ }^{\circ} \mathrm{OH}$; (10) 1 equiv $\mathrm{HOCl}$; (11) 1 equiv ONOO-. (B) Fluorescence increases of HKGreen-4 $(1 \mu \mathrm{M})$ towards $\mathrm{ONOO}^{-}$(1 equiv) in the presence of various ROS and RNS. (1) 1 equiv $\mathrm{ONOO}^{-}$only; (2) 10 equiv $\mathrm{ROO}^{\bullet}$ plus 1 equiv $\mathrm{ONOO}^{-}$; (3) 10 equiv ${ }^{1} \mathrm{O}_{2}$ plus 1 equiv $\mathrm{ONOO}^{-}$; (4) 10 equiv $\mathrm{H}_{2} \mathrm{O}_{2}$ plus 1 equiv $\mathrm{ONOO}^{-}$; (5) 10 equiv ${ }^{\bullet} \mathrm{NO}$ plus 1 
equiv $\mathrm{ONOO}^{-}$; (6) 10 equiv $\mathrm{O}_{2}^{\bullet-}$ plus 1 equiv $\mathrm{ONOO}^{-}$; (7) 10 equiv $\mathrm{NO}_{2}$ plus 1 equiv $\mathrm{ONOO}^{-}$; (8) 10 equiv $\mathrm{CO}_{3}{ }^{--}$plus 1 equiv $\mathrm{ONOO}^{-}$; (9) 1 equiv ${ }^{\bullet} \mathrm{OH}$ plus 1 equiv $\mathrm{ONOO}^{-}$; (10) 1 equiv $\mathrm{HOCl}_{\text {plus }}$ 1 equiv $\mathrm{ONOO}^{-}$.

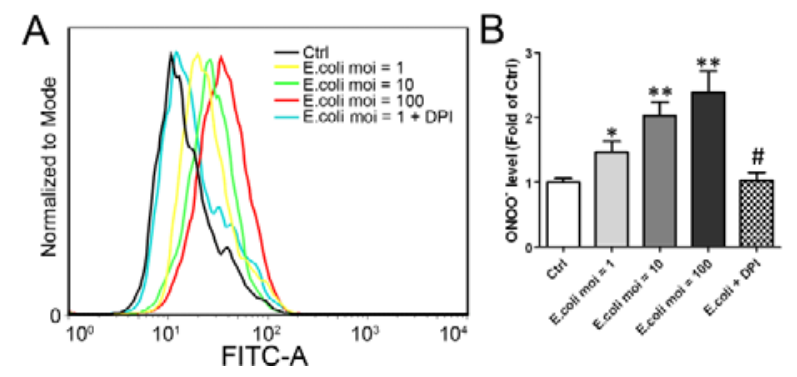

Figure S18. Flow cytometry analysis of HKGreen-4-loaded live RAW 264.7 macrophages in response to stimulation with heat-killed E. coli. Cells were challenged with heat-killed E. coli $(\mathrm{moi}=1,10,100)$ for $15 \mathrm{~h}$ and incubated with $\mathbf{H K G r e e n}-4 \mathbf{A}(20 \mu \mathrm{M})$ at $37^{\circ} \mathrm{C}$ for $30 \mathrm{~min}$. Cells were then harvested, resuspended in PBS and analyzed by flow cytometry (Becton-Dickinson LSRII, Franklin Lakes, NJ, USA). (A) Representative histogram of $\mathrm{ONOO}^{-}$generation in macrophages upon stimulation with heat-killed E. coli (moi $=1,10,100)$ in the presence or absence of DPI (50 nM). (B) Statistic analysis of traces in $(\mathrm{A})$, data presented as mean relative fluorescence intensity $\pm \mathrm{SD}(n=3) .{ }^{*} p<0.05$ and ${ }^{* *} p<0.01$, versus control group; \#p<0.05, versus E. coli (moi $=1$ ) group.

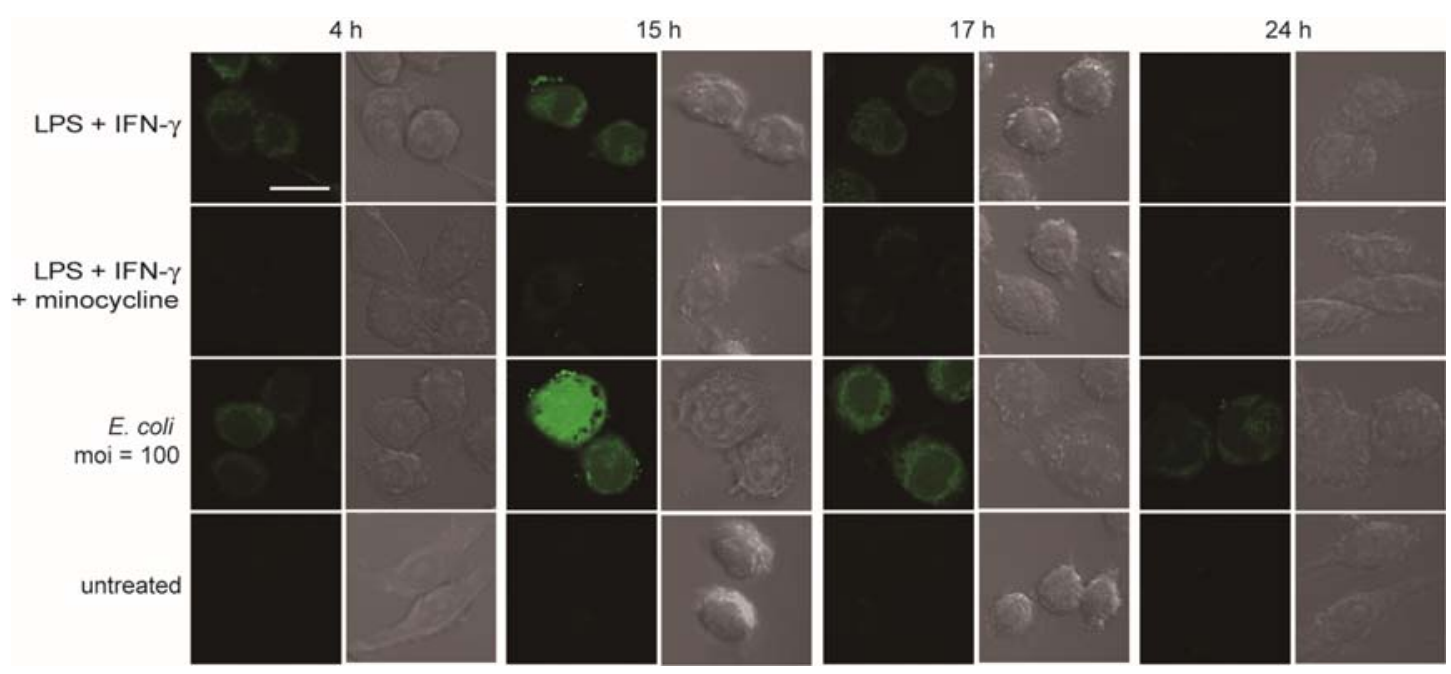

Figure S19. Complete figure of Figure 3A including bright field images. 

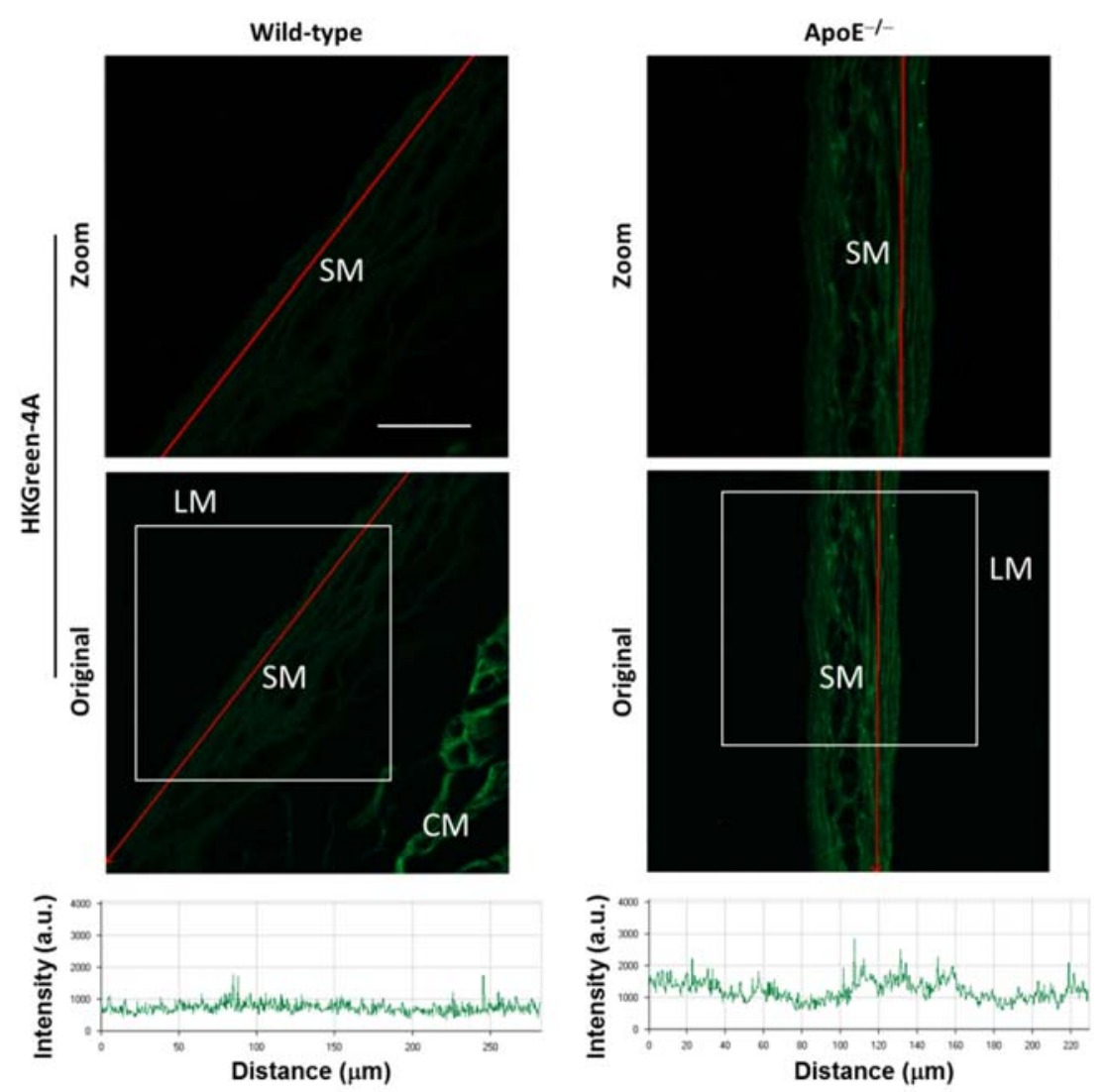

Figure S20. Original uncropped images of Figure 5. SM, CM, and LM refer to smooth muscles, cardiac muscles, and lumen, respectively. The white rectangles indicate the cropped regions shown in Figure 5. Scale bar represents $50 \mu \mathrm{m}$. 

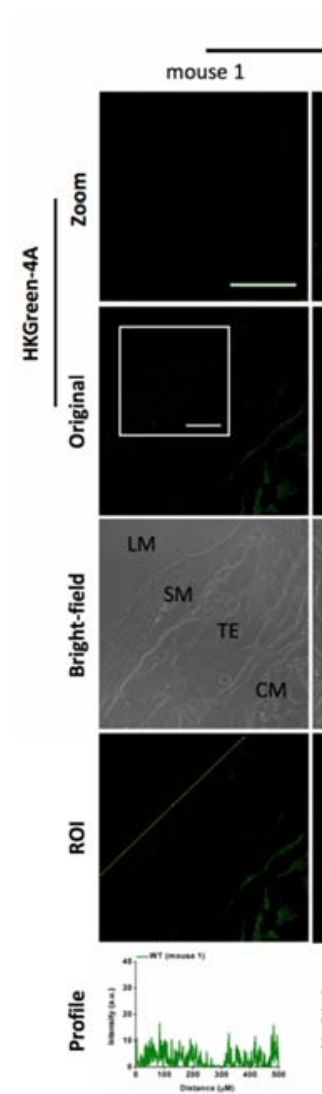

Wild-type

mouse 2
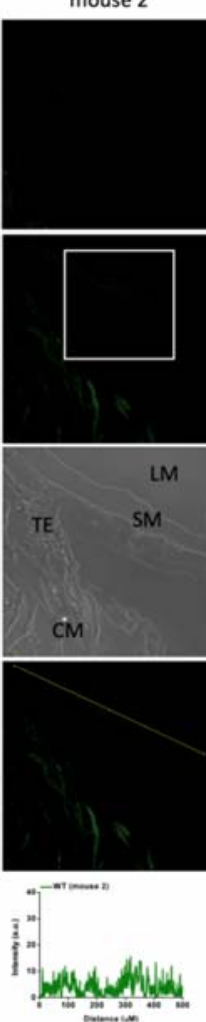

mouse 3
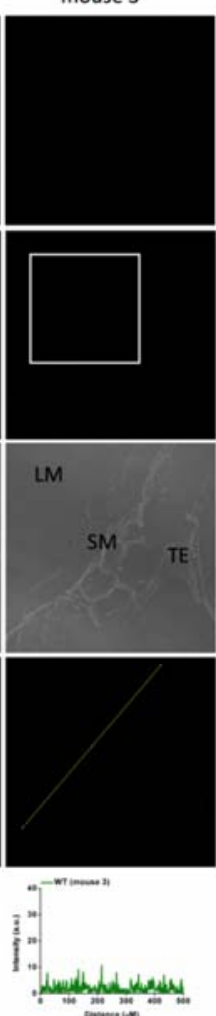
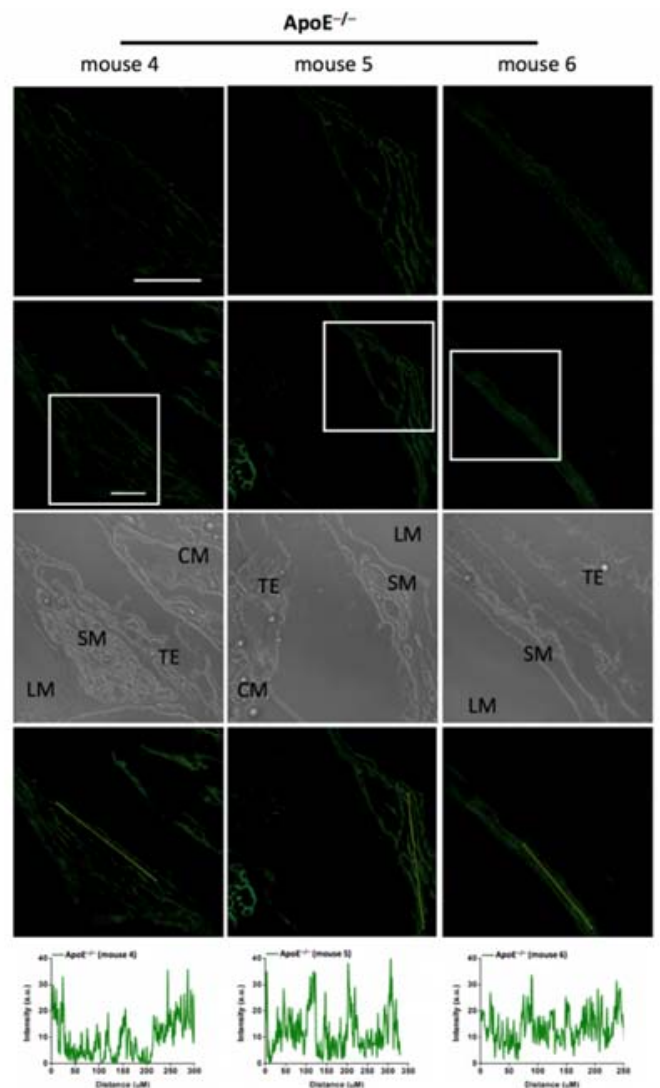

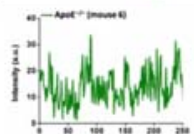

Figure S21. Original uncropped images of Figure S16. SM, CM, LM, and TE refer to smooth muscles, cardiac muscles, lumen, and tunica externa, respectively. The white rectangles indicate the cropped regions shown in Figure S16. Profiles of fluorescence intensity of regions of interest (ROI) are shown as indicated. Scale bar represents $50 \mu \mathrm{m}$. 
8. NMR spectra
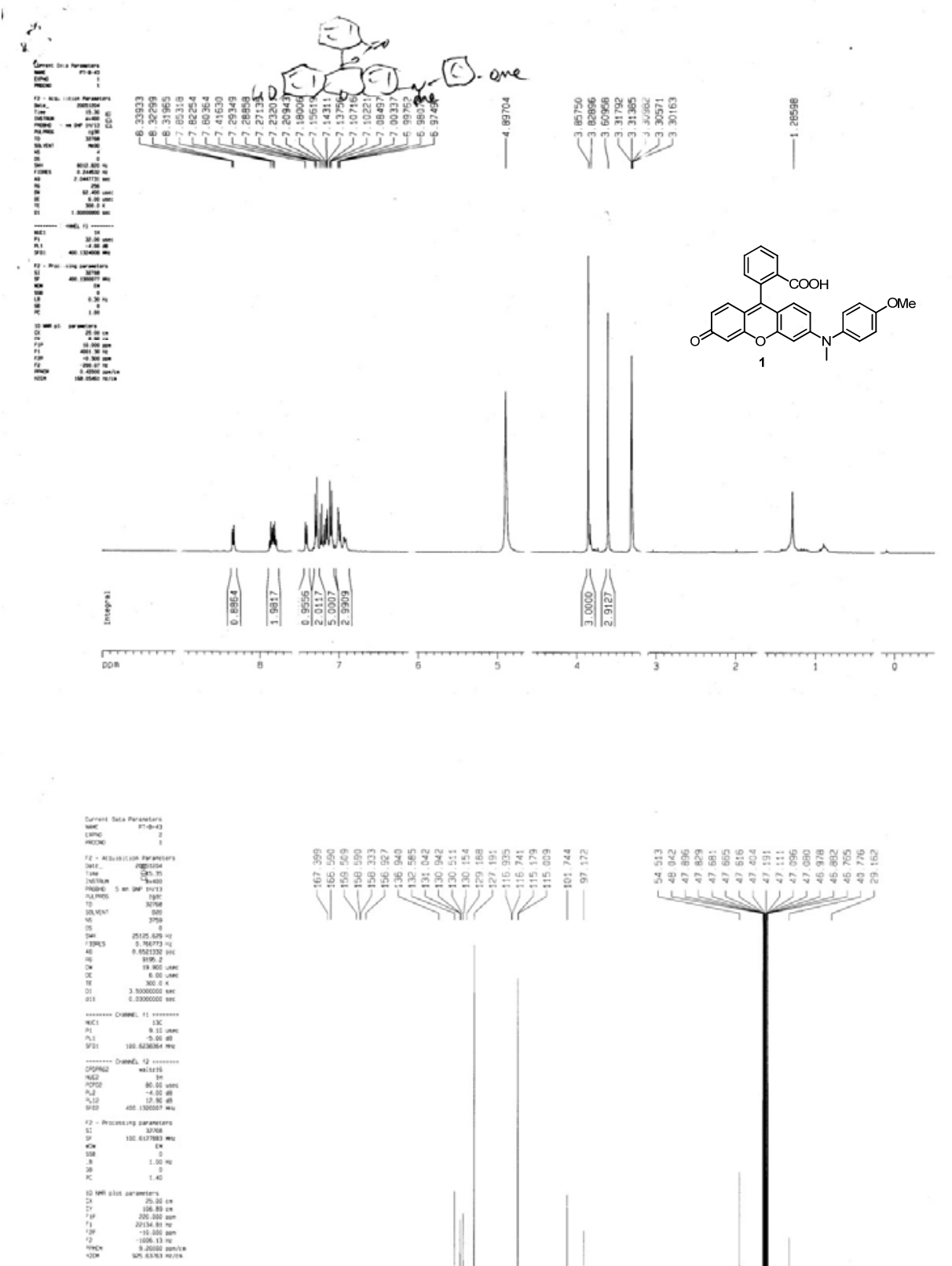

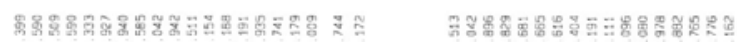

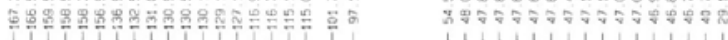

VWu

absis
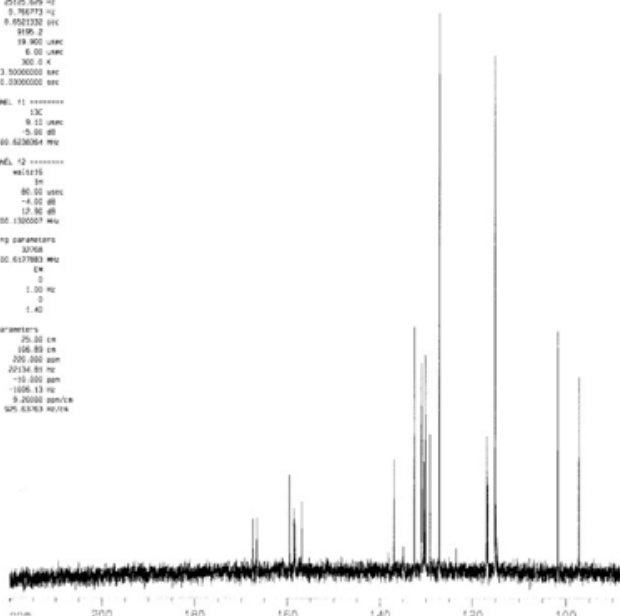

Figure S22. ${ }^{1} \mathrm{H}$ and ${ }^{13} \mathrm{C}$ NMR spectra of compound 1. 

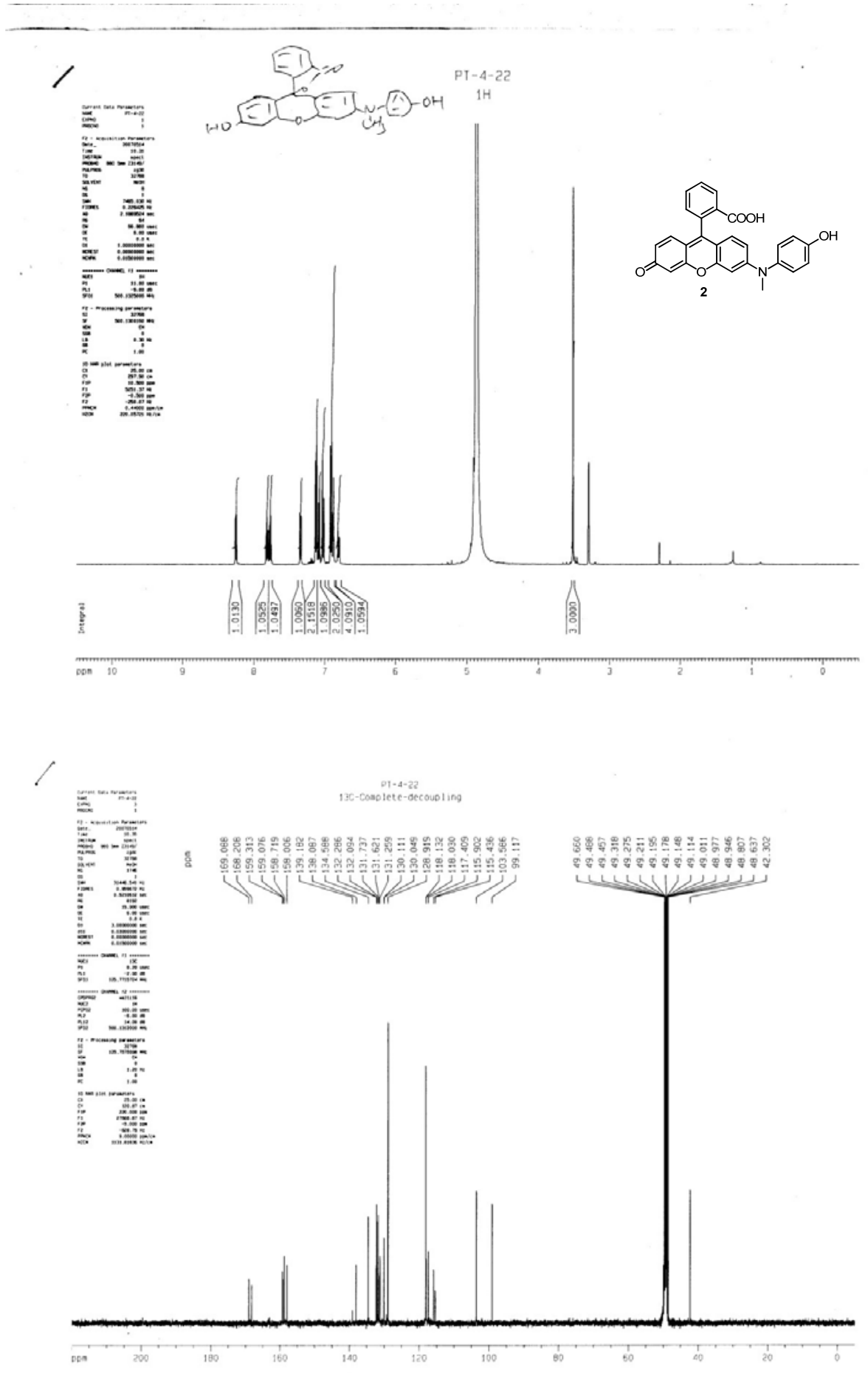

Figure S23. ${ }^{1} \mathrm{H}$ and ${ }^{13} \mathrm{C}$ NMR spectra of compound 2. 

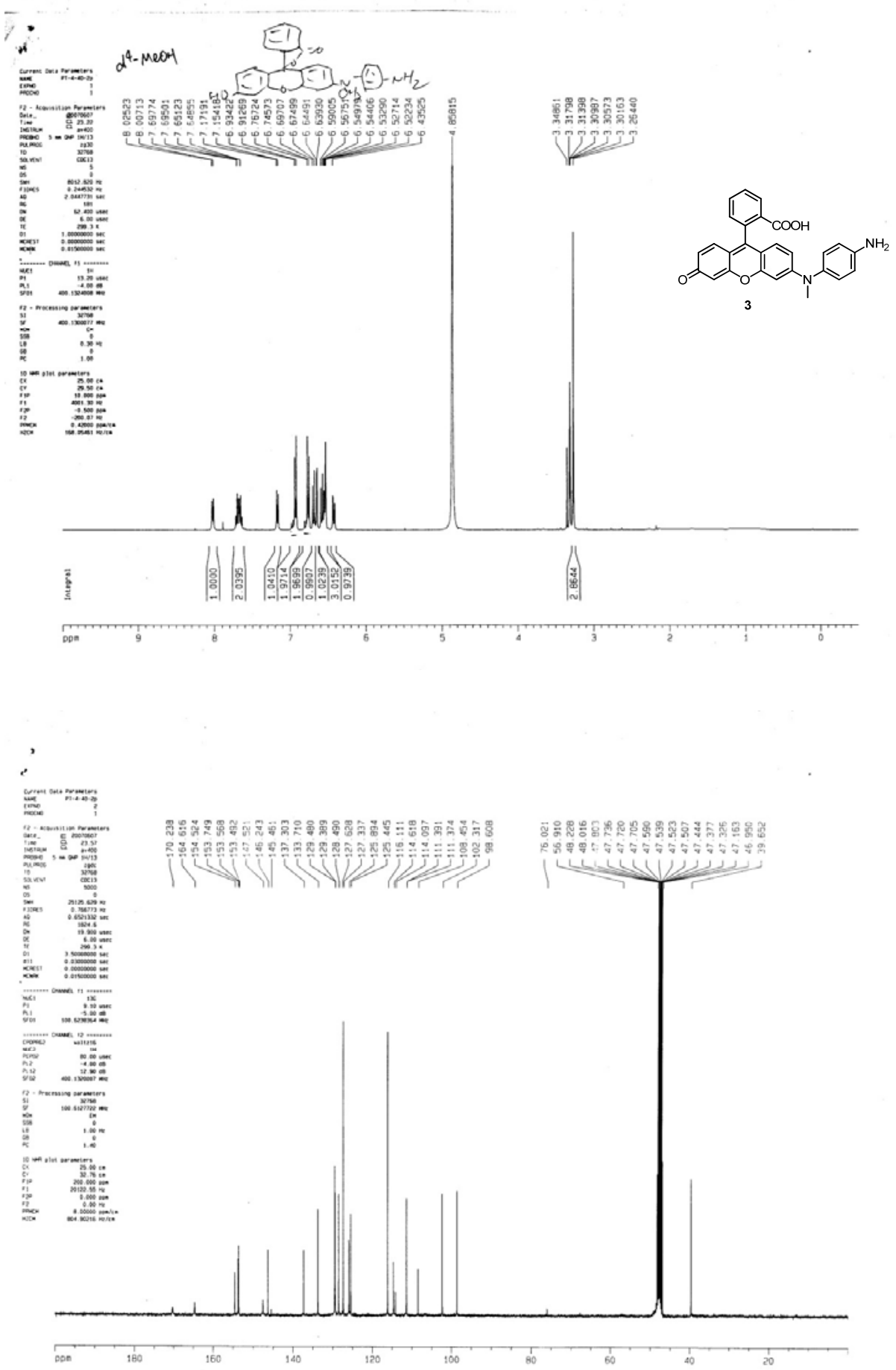

Figure S24. ${ }^{1} \mathrm{H}$ and ${ }^{13} \mathrm{C}$ NMR spectra of compound 3. 


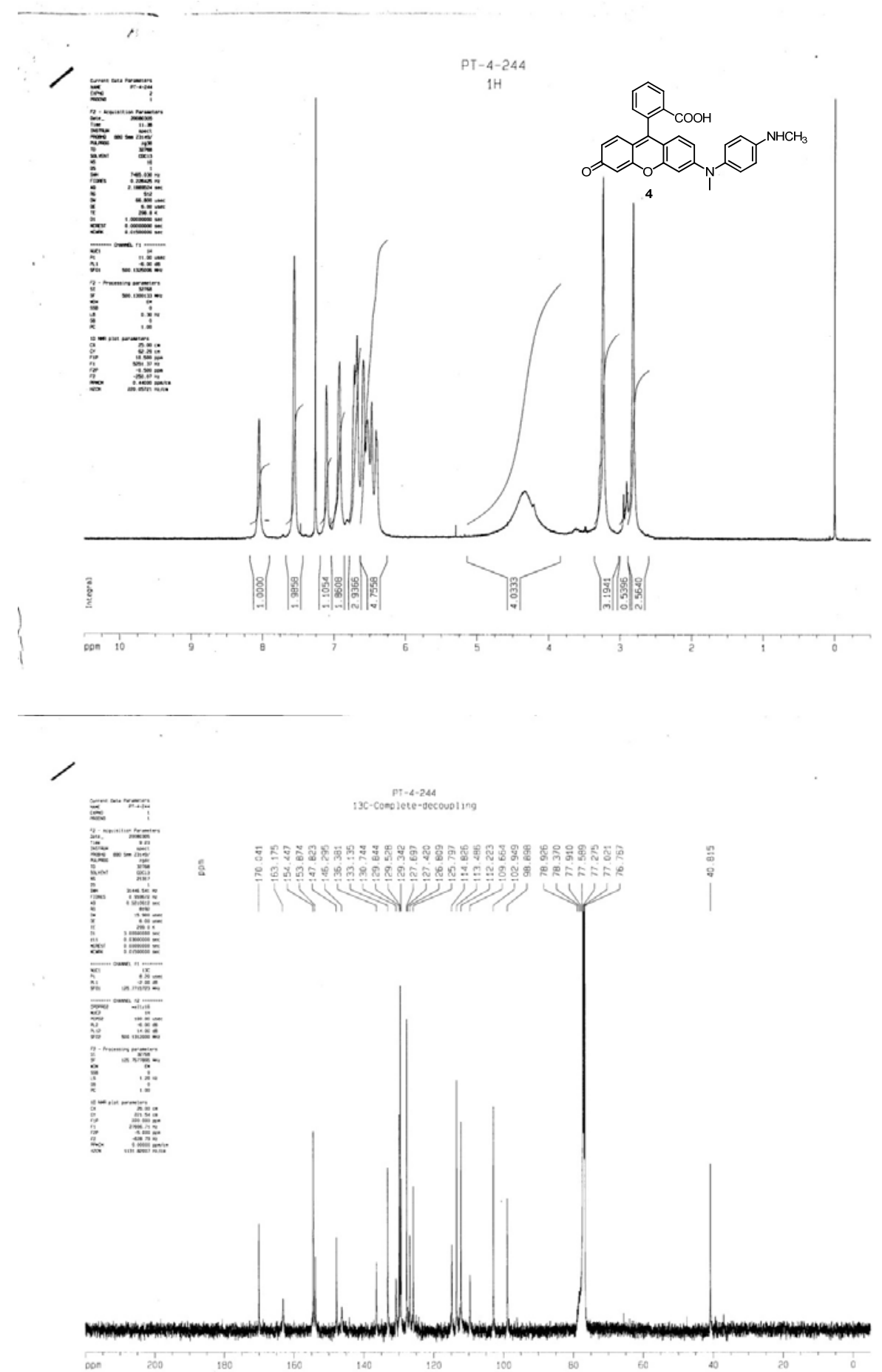

Figure S25. ${ }^{1} \mathrm{H}$ and ${ }^{13} \mathrm{C}$ NMR spectra of compound 4. 


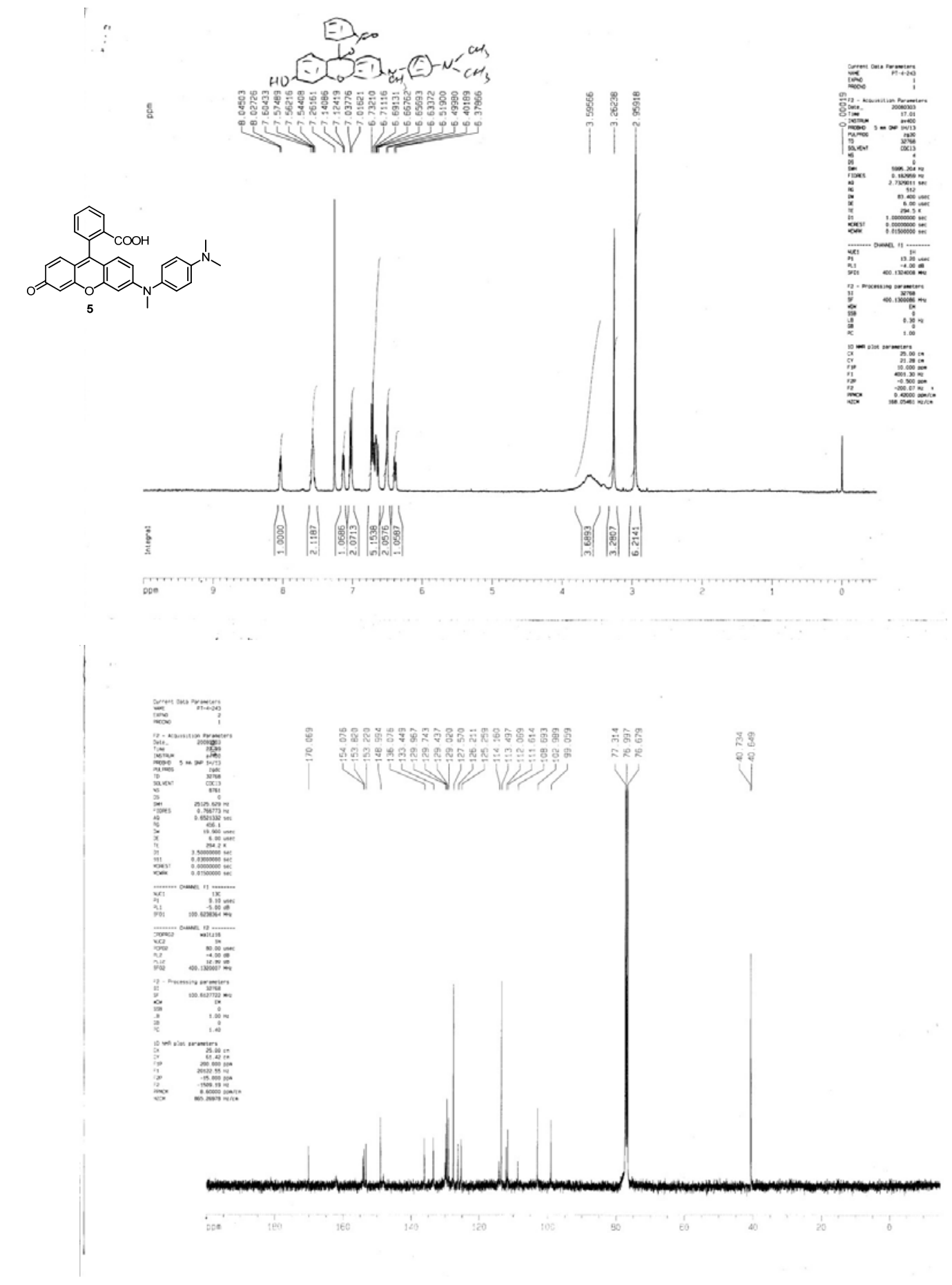

Figure S26. ${ }^{1} \mathrm{H}$ and ${ }^{13} \mathrm{C}$ NMR spectra of compound $\mathbf{5}$. 

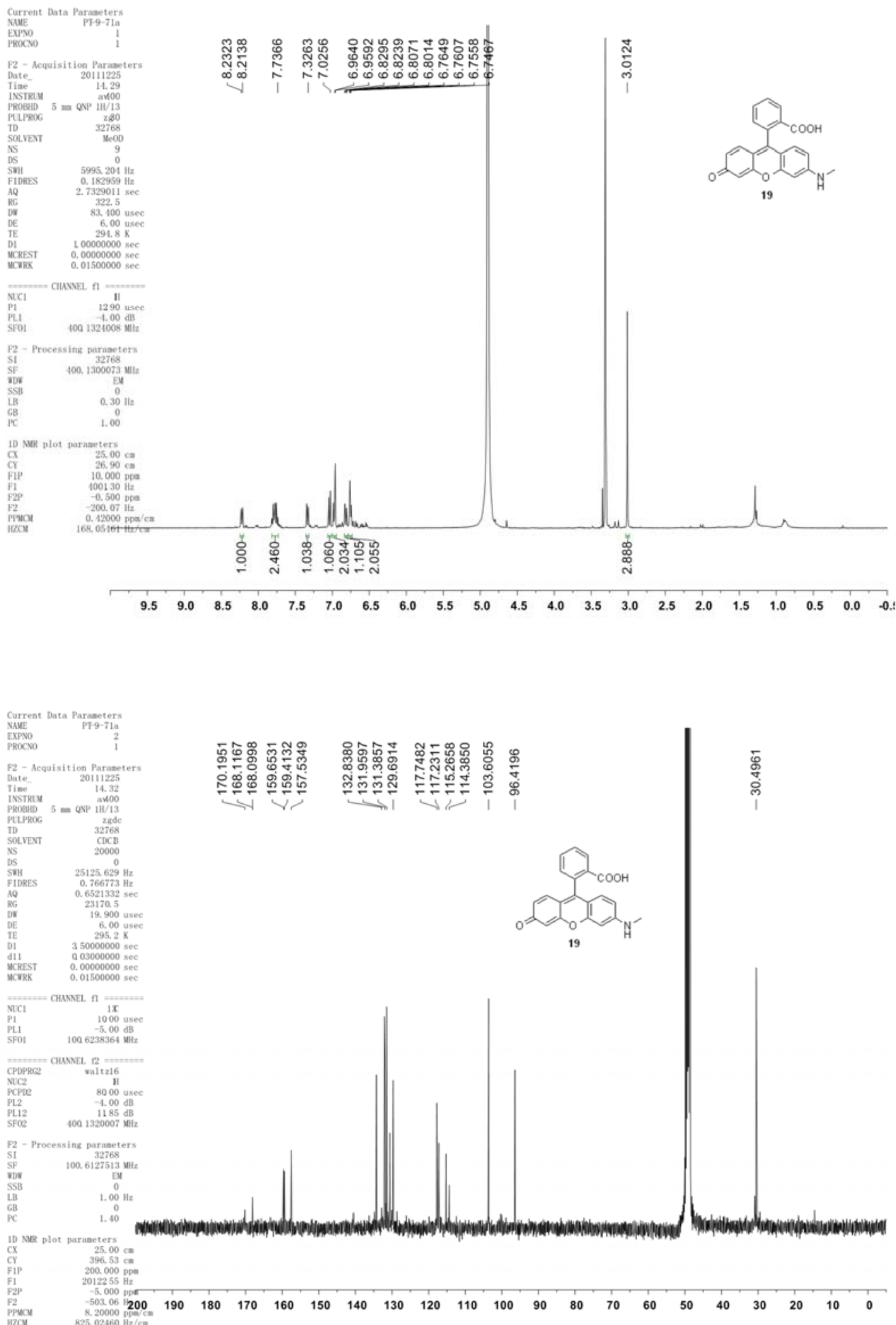

Figure S27. ${ }^{1} \mathrm{H}$ and ${ }^{13} \mathrm{C}$ NMR spectra of compound 19. 

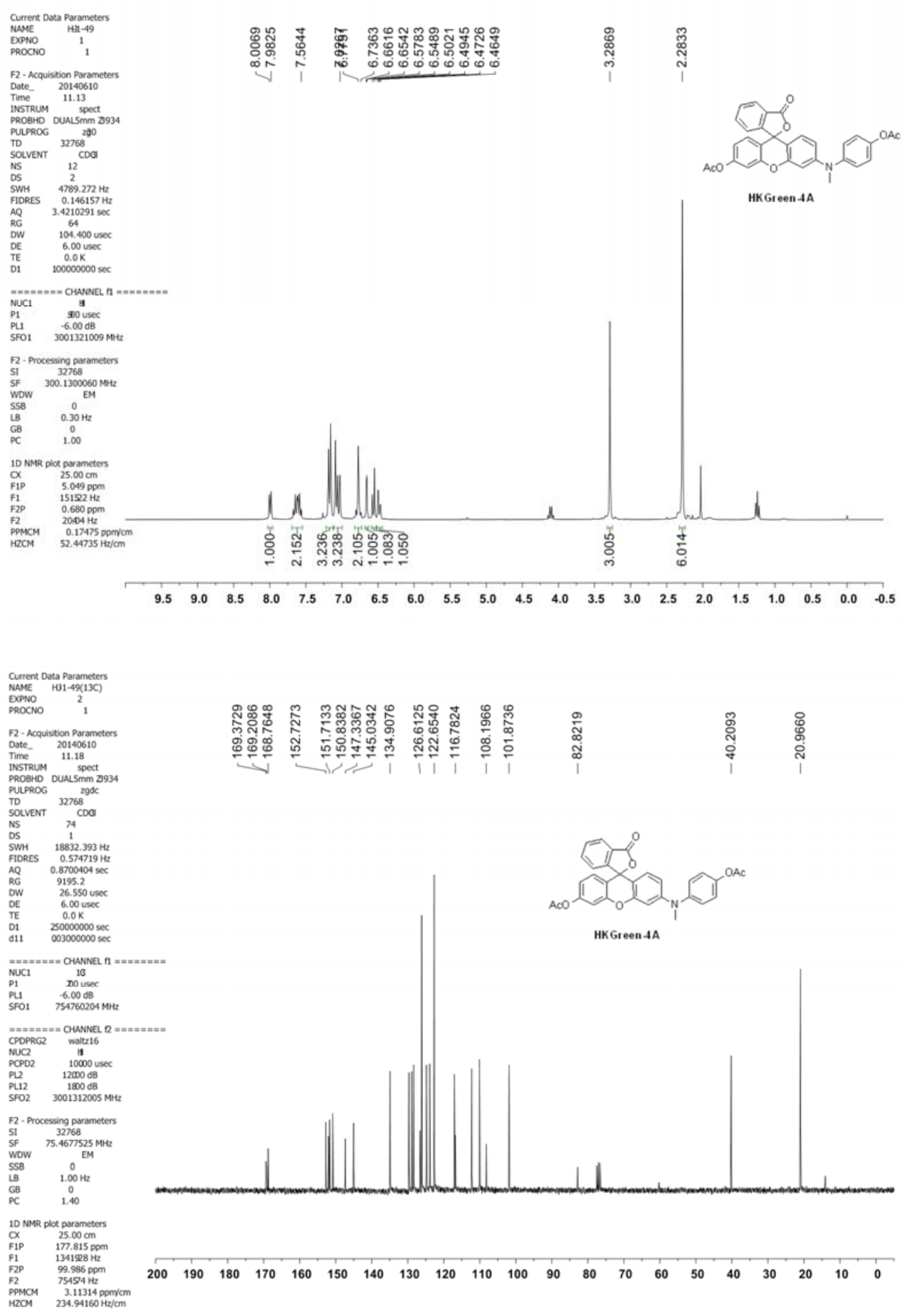

Figure S28. ${ }^{1} \mathrm{H}$ and ${ }^{13} \mathrm{C}$ NMR spectra of HKGreen-4A. 


\section{Reference}

(1) Peng, T.; Yang, D. Org. Lett. 2010, 12, 496.

(2) Pluth, M. D.; McQuade, L. E.; Lippard, S. J. Org. Lett. 2010, 12, 2318.

(3) (a) Medinas, D. B.; Toledo, J. J. C.; Cerchiaro, G.; do-Amaral, A. T.; de-Rezende, L.; Malvezzi, A.; Augusto, O. Chem. Res. Toxicol. 2009, 22, 639. (b) Lapenna, D.; Ciofani, G.; Cuccurullo, C.; Neri, M.; Giamberardino, M. A.; Cuccurullo, F. Free Radic. Res. 2012, 46, 1387. 